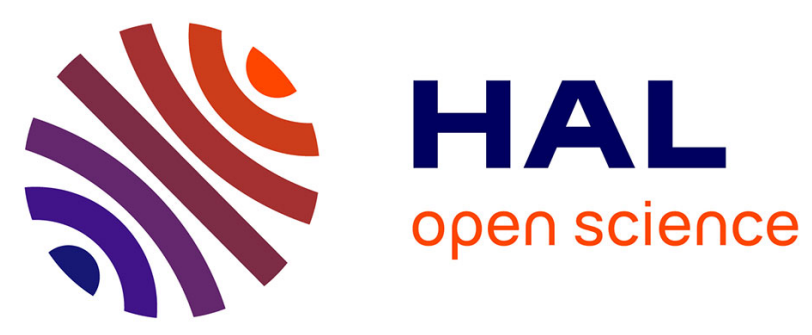

\title{
Optimal Design of Bus Routes for Different Vehicle Types Considering Various Driving Regimes and Environmental Factors
}

Yue Su, Xiaobo Liu, Guo Lu, Wenbo Fan

\section{- To cite this version:}

Yue Su, Xiaobo Liu, Guo Lu, Wenbo Fan. Optimal Design of Bus Routes for Different Vehicle Types Considering Various Driving Regimes and Environmental Factors. Transportation Research Record, 2019, 2673 (6), pp.299-316. 10.1177/0361198119841566 . hal-02385828

\section{HAL Id: hal-02385828 \\ https://hal.science/hal-02385828}

Submitted on 29 Nov 2019

HAL is a multi-disciplinary open access archive for the deposit and dissemination of scientific research documents, whether they are published or not. The documents may come from teaching and research institutions in France or abroad, or from public or private research centers.
L'archive ouverte pluridisciplinaire HAL, est destinée au dépôt et à la diffusion de documents scientifiques de niveau recherche, publiés ou non, émanant des établissements d'enseignement et de recherche français ou étrangers, des laboratoires publics ou privés. 


\section{Transportation Research Record \\ OPTIMAL DESIGN OF BUS ROUTES FOR DIFFERENT VEHICLE TYPES CONSIDERING VARIOUS DRIVING REGIMES AND ENVIRONMENTAL FACTORS

\author{
--Manuscript Draft--
}

\begin{tabular}{|c|c|}
\hline Full Title: & $\begin{array}{l}\text { OPTIMAL DESIGN OF BUS ROUTES FOR DIFFERENT VEHICLE TYPES } \\
\text { CONSIDERING VARIOUS DRIVING REGIMES AND ENVIRONMENTAL FACTORS }\end{array}$ \\
\hline Abstract: & $\begin{array}{l}\text { As a major part of public transportation system, bus transit has been regarded as an } \\
\text { effective mode to alleviate the traffic congestion and solve vehicle emission problem. } \\
\text { The performance of bus transit system depends largely on its design of proper stop } \\
\text { locations. In this reasearch, we proposed a multi-period continuum model (peak hour } \\
\text { and off-peak hour) to optimize the design of a bus route for four different vehicle types } \\
\text { (i.e., supercharge bus, Compressed Natural Gas (CNG) bus, Lithium-ion battery bus, } \\
\text { and diesel bus) considering driving regimes and the pollutant cost. Inter-stop driving } \\
\text { regimes, including acceleration, cruising, coasting, and deceleration, are explicitly } \\
\text { introduced into the optimization to determine whether and how the coasting regime } \\
\text { should be undertaken in the tradeoff between vehicle's commercial speed and the } \\
\text { operating cost. The comparison for the cost effectiveness of each alternative has been } \\
\text { investigated in a life span with respect to different vehicle types. The method has been } \\
\text { implemented in the real-word bus route } 7 \text { in Yaan City (China). The numerical } \\
\text { experiments suggest that through optimization, the total system cost has been saved } \\
\text { by more than } 50 \% \text {. The results of continuum model are validated by the comparison } \\
\text { with the discretized results, and the outcomes are closely located in neighborhood } \\
\text { (with error less than } 3 \% \text { ). The life-cycle cost of four vehicle types is finally analyzed, } \\
\text { and the result indicates that due to the high purchase prices, it's difficult for clean- } \\
\text { energy buses to outperform conventional buses in a life cycle (normally } 8 \text { years), } \\
\text { unless with subsidies provided. }\end{array}$ \\
\hline Manuscript Classifications: & $\begin{array}{l}\text { Public Transportation Planning and Development AP025; Model; Transit; Transit } \\
\text { Management and Performance AP010; Planning; Public Transportation }\end{array}$ \\
\hline \multicolumn{2}{|l|}{ Manuscript Number: } \\
\hline Article Type: & Publication \& Presentation \\
\hline Order of Authors: & Yue Su \\
\hline
\end{tabular}




\section{OPTIMAL DESIGN OF BUS ROUTES FOR DIFFERENT VEHICLE TYPES CONSIDERING VARIOUS DRIVING REGIMES AND ENVIRONMENTAL FACTORS}

Yue Su

7 School of Transportation and Logistic, Southwest Jiaotong University

8 No.999, Xi'an Street, ChengDu, SiChuan, China, 611756

9 Tel: +86-13908214147 Email: yuesu@my.swjtu.edu.cn

Xiaobo Liu, Ph.D.

12 School of Transportation and Logistic, Southwest Jiaotong University

13 No.999, Xi' an Street, ChengDu, SiChuan, China, 611756

14 Tel: +86-13688002461 Email: xiaobo.liu@ swjtu.cn

\section{Guo Lu}

School of Transportation and Logistic, Southwest Jiaotong University No.999, Xi' an Street, ChengDu, SiChuan, China, 611756

Tel: +86-18620366066 Email: 496069232@qq.com

Wenbo Fan, Ph.D., Corresponding Author

School of Transportation and Logistic, Southwest Jiaotong University

No.999, Xi'an Street, ChengDu, SiChuan, China, 611756

Tel: +86-13658082981 Email: wbfan@ swjtu.edu.cn

Word count: 6,127 words text +5 tables x 250 words $($ each $)=7,377$ words 


\section{ABSTRACT}

2 As a major part of public transportation system, bus transit has been regarded as an effective mode 3 to alleviate the traffic congestion and solve vehicle emission problem. The performance of bus

4 transit system depends largely on its design of proper stop locations. In this reasearch, we proposed 5 a multi-period continuum model (peak hour and off-peak hour) to optimize the design of a bus 6 route for four different vehicle types (i.e., supercharge bus, Compressed Natural Gas (CNG) bus, 7 Lithium-ion battery bus, and diesel bus) considering driving regimes and the pollutant cost.

8 Inter-stop driving regimes, including acceleration, cruising, coasting, and deceleration, are 9 explicitly introduced into the optimization to determine whether and how the coasting regime 10 should be undertaken in the tradeoff between vehicle's commercial speed and the operating cost. 11 The comparison for the cost effectiveness of each alternative has been investigated in a life span 12 with respect to different vehicle types. The method has been implemented in the real-word bus 13 route 7 in Yaan City (China). The numerical experiments suggest that through optimization, the 14 total system cost has been saved by more than $50 \%$. The results of continuum model are validated 15 by the comparison with the discretized results, and the outcomes are closely located in 16 neighborhood (with error less than 3\%). The life-cycle cost of four vehicle types is finally 17 analyzed, and the result indicates that due to the high purchase prices, it's difficult for clean-energy 18 buses to outperform conventional buses in a life cycle (normally 8 years), unless with subsidies 19 provided. Types 


\section{INTRODUCTION}

With the astounding growth in automobile ownership, most cities in China have to face a number of transportation related issues such as rapid environmental deterioration and serious congestion problem in urban area. The pollutants emitted such as $\mathrm{CO}, \mathrm{VOC}$, and $\mathrm{NO}_{\mathrm{x}}$, bring unpleasant impacts on the air quality as well as the public health. Zero-emission buses, such as battery electric buses and supercharge buses, entail environmental friendliness, and have been recognized as a new solution of environmental problem and traffic congestion. Supercharge bus is the newest bus type in the market and it utilizes super capacitor as power source, which has the advantages of fast charging and discharging ability. Compared with battery electric bus, supercharge bus takes far less time to charge, and it doesn't need to replace batteries in a life cycle. Many cities in China have spared no effort in developing a new transit network with clean-energy buses. For instance, all the conventional buses (i.e., 16,000 CNG and diesel buses) in Shenzhen will be replaced with electric buses by the end of 2018 (1). Despite the environmental advantages of the new-energy buses, the expensive purchase price is an obstacle that impedes the progress of the shifting to clean energy. For example, the unit vehicle price of an electrical bus is almost three times more expensive than conventional bus (2). In order to yield a scientific assessment between clean-energy buses and conventional buses, it is necessary to take the technical and economical characteristics of different bus types into consideration to assess their cost competiveness.

To make the transit system more efficient, it is necessary for designers to provide a delicated transit system with stops being well located. There are two basic approaches for tackling Transit Route Design (TRD) problem. One is discrete approach which has been frequently used in the TRD problem. Studies (3-6) applied discrete approach to decide the optimal stop locations. The basic idea of discrete model is to determine optimal set of stops for a given OD matrix and predict travel time per link on the route (7). Dynamic programming is largely used in the optimization. The disadvantage of this approach is the computational inefficiency because of the numerous decision variables.

Another approach is the Continuum Approximation (CA) approach. Previous studies (8-18) employed CA approach to obtain the optimal design of a transit system, where a small number of continuous functions are inputed; e.g., lines and stations are specified in terms of the spacing between them (19). Some other parameters including headway, bus capacity, fleet size, have also been used in the optimization model (20-21). The pioneering work of CA approach employed in transit route design seems to be the study of Newell (8), in which the mechanics of CA approach was elaborated. After that, Vaughan and Cousins (14) took advantage of a continuous stop density function to determine the number of stops so as to minimize user's travel time on a single corridor. The demand pattern is a "many-to-many" demand pattern to reflect the spatial heterogeneity of demand and is also presented in a continuous form. Later, Wirashinghe and Ghoneim (12) proposed a more general continuous model to minimize the total system cost which consists of user cost and operator cost with respect to a "many-to-many" demand pattern. The stop density is expressed as a function of location and the integral of stop density function is firstly used as the method to find optimal stop locations. Recently, Medina-Tapia et al. (16) employed CA-based transit design model to a single bus corridor considering multiple periods (peak hour and off-peak hour). A bi-directional stop density functions and multi-period headways are obtained. Further, Amirgholy et al. (22) proposed a CA model to minimize user cost, agency cost, and pollutant cost in a congested network. It seems to be the only CA-based work that considering environmental impacts into transit route design.

The theme of this study is to optimize the bus route design for a single corridor considering 
different bus types of which the inter-stop driving regimes are explicitly modeled. In the proposed model, the objective function is to minimize the total system cost, as a sum of user cost, operator cost, as well as pollutant cost. The model is based on continuum approximation and its accuracy is verified by a discrete approach. A case study is furnished on a bus route in Yaan City (China). The contributions of this work include: the environmental factors and inter-stop driving regimes are considered in transit route design model to analyze the system cost of different vehicle types. By intergrating the optimized system cost (on a per day basis) with life-cycle cost analysis, it can provide operator insight to choose appropriate vehicle type. Furthermore, the optimized coasting speeds for different bus types have been analyzed as well as the effect of coasting regimes on operation cost, which can be implemented in practical selection of driving regimes for different bus types.

The remainder of this paper is organized as follows. Next section introduces the optimization model, with variables' definitions and formulations of the CA model, respectively. In the section, a non-linear total cost minimization problem is introduced. After that, the numerical application is conducted by using the real demand data, and the obtained results are analyzed. In the end of section 3, a cost-effectiveness analysis among different vehicle types has been elaborated. Last section concludes the findings and indicates further extensions.

\section{METHODOLOGY}

The proposed model contains a bus corridor of length $L$, operating in two directions (denoted by $r \in\{e b, w b\}$, indicating eastbound and westbound, respectively). The bus travelling in each direction of the corridor stops at each stop. The studied periods are: peak hour period and off-peak hour period (denoted by $i \in\{p k, o p\}$, indicating peak-hour period and off-peak hour period, respectively) whose service headways are different to reflect the demand variation but equal in both directions. To facilitate organization, the developed model is based on a few assumptions as follows:

1. The value of time for all passengers is assumed to be the same, regardless the citizen's status, income, etc.

2. Passengers choose the nearest stop to board or alight bus.

3. There is no congestion on the corridor, so bus acceleration or deceleration results from whether it has to stop or start at bus stop. For the segment between two stops, different driving regimes could be adopted regarding whether coasting occurs, for instance. In addition, the acceleration and deceleration rates are constant in this study.

4. No bus congestion is assumed to occur at bus stops, so each bus opens its door as soon as it arrives at a stop.

In this section, we will first introduce the objective function $T C_{m}$, which represents the total system cost (on a per day basis), with $m \in\{S C, C N G, L i, D i\}$, representing supercharge,

$40 \mathrm{CNG}$, Lithium-ion, and diesel buses, respectively. $T C_{m}$ contains user cost $C_{u, m}$, operator cost $C_{o, m}$, 41 and pollutant cost $C_{P, m}$ :

$44 T C_{m}=C_{u, m}+C_{o, m}+C_{P, m}$, 
$33 C_{a, m}=\sum_{r=e b, w b} \sum_{i=p k, o p} \int_{0}^{L} \frac{\left(a l_{r, i}(x)+b o_{r, i}(x)\right) \cdot T_{i} \cdot \theta_{a}}{4 \cdot \delta_{m, r}(x) \cdot v_{a}} d x$,

$C_{u, m}=C_{a, m}+C_{w, m}+C_{v, m}$

$m \in\{S C, C N G, L i, D i\}$

$$
C_{o, m}=C_{s, m}+\left(C_{f, m}^{f}+C_{f, m}^{h}+C_{f, m}^{d}\right)+\left(C_{f, m}^{c}+C_{f, m}^{c o}+C_{f, m}^{a d}\right),
$$

$m \in\{S C, C N G, L i, D i\}$

\section{Continuum Approximation Models}

User Cost

$$
m \in\{S C, C N G, L i, D i\}, i \in\{p k, o p\}, r \in\{e b, w b\}
$$

where

$\theta_{a}:$ value of access time (dollar per passenger hour);

The user cost includes three parts: the cost that passengers have to access or egress the stop $\left(C_{a, m}\right)$, the cost that passengers spent waiting at the stop $\left(C_{w, m}\right)$, and the in-vehicle cost $\left(C_{v, m}\right)$.

The operator cost entails those of: the stop construction and maintenance cost $C_{s, m}$; the Vehicle Hour Traveled (VHT) related cost (i.e., the cost associated with fleet size $C_{f, m}^{f}$, the cost associated with driver salary $C_{f, m}^{h}$, and idling cost $C_{f, m}^{d}$ ); Vehicle Kilometer Traveled (VKT) related cost (i.e., the cost associated with distance under cruising regime $C_{f, m}^{c}$, coasting regime $C_{f, m}^{c o}$, and acceleration and deceleration regimes $C_{f, m}^{a d}$ ). The operator cost is thus given by:

The expression of pollutant cost $C_{P, m}$ will be formulated later in Equation 30 and 31 .

Seeing in Equation 1a, each cost item will be explained in brief expression in this part.

For users who access and egress at point $x$ on the corridor, the access/egress cost is computed by multiplying the number of users, the value of access time, and the average walking time. Assuming that the distribution of demand in the neighborhood of $x$ is uniformed, the expected walking distance can be formulated as $\frac{1}{4 \cdot \delta_{m, r}(x) \cdot v_{a}}$, thus the access/egress cost is: 
$1 a l_{r, i}(x)$ : number of passengers who would like to alight at point $x(x \in[0, L])$. Noting that $r \in$ $2\{e b, w b\}, i \in\{p k, o p\}$ (passenger per kilometer per hour);

$3 b o_{r, i}(x)$ : number of passengers who would like to board at point $x(x \in[0, L])$. Noting that $r \in$ $4\{e b, w b\}, i \in\{p k, o p\}$ (passenger per kilometer per hour);

$5 \quad T_{i}$ : duration of period $i$, with $i \in\{p k, o p\}$ (hour);

$6 \delta_{m, r}(x)$ : stop density function, with $m \in\{S C, C N G, L i, D i\}, r \in\{e b, w b\}$ (number of stops per 7 kilometer);

$8 v_{a}$ : average walking speed for passengers accessing and egressing bus stop; (kilometer per hour);

9 The daily waiting cost is considered as the product of average waiting time per passenger,

10 the number of boarding passengers, and the value of waiting time. Considering that waiting 11 passengers will get on the first bus that passes by, the waiting time of passengers will increases 12 linearly with average headway between buses, $h_{i}$. The expected passenger's waiting time will be 13 half of headway if bus's arrival is perfectly regular. Therefore, the expression for user waiting cost 14 is given as follow:

$17 \quad C_{w, m}=\sum_{r=e b, w b} \sum_{i=p k, o p} \int_{0}^{L} b o_{r, i}(x) \cdot T_{i} \cdot \frac{h_{i}}{2} \cdot \theta_{w} d x$,

$m \in\{S C, C N G, L i, D i\}, i \in\{p k, o p\}, r \in\{e b, w b\}$

where:

$\theta_{w}$ : value of waiting time (dollar per passenger hour);

$h_{i}$ : the average headway, with $i \in\{p k, o p\}$ (hour);

The in-vehicle cost is the cost generated by all on board passengers when bus is operating between stops. It contains the cost accounted for bus travelling and for bus idling. Different driving regimes might be conducted while bus is moving to next stop and it is essential to fully understand the driving scenarios that could happen. Generally, there are four basic driving regimes (i.e., acceleration, cruising, coasting, and deceleration).

The bus's travel time between stops depends on whether a transit vehicle can reach its maximum speed or not. Supposed $S_{c}$ to be the critical distance for completing a perfect acceleration to cruising speed and a perfect deceleration from the cruising speed. For a stop spacing (represented as $\left.\frac{1}{\delta_{m, r}(x)}\right)$, here are four driving scenarios:

Scenario 1: No coasting and cruising, $\frac{1}{\delta_{m, r}(x)} \leq S_{c}$

In this case, the inter-stop travel time $t_{1}$ consist of two parts, the time for accelerating to 


$$
t_{a 1}=\frac{v_{s}}{a_{v}}
$$

2

3

$4 \quad t_{b 1}=\frac{v_{s}}{d_{v}}$
6

$21 \quad t_{m, r, i, 1}^{v}(x)=\sqrt{\frac{2\left(a_{v}^{2}+d_{v}^{2}\right) \cdot \delta_{m, r}(x)}{\left(a_{v}+d_{v}\right) \cdot a_{v} \cdot d_{v}}}, \frac{1}{\delta_{m, r}(x)} \leq S_{c}$,

$$
t_{2}=t_{a 2}+t_{c 2}+t_{b 2}
$$

$$
34 t_{a 2}=\frac{v_{c, i}}{a_{v}}
$$


1

2

$3 \quad t_{c 2}=\frac{1}{\delta_{m, r}(x) \cdot v_{c, i}}-\frac{v_{c, i}}{2 a_{v}}-\frac{v_{c, i}}{2 d_{v}}$

4

5

$6 \quad t_{b 2}=\frac{v_{c, i}}{d_{v}}$

$7 m \in\{S C, C N G, L i, D i\}, i \in\{p k, o p\}, r \in\{e b, w b\}$;

$13 t_{m, r, i, 2}^{v}(x)=\frac{v_{c, i} \cdot \delta_{m, r}(x)}{2} \cdot\left(\frac{1}{a_{v}}+\frac{1}{d_{v}}\right)+\frac{1}{v_{c, i}}, \frac{1}{\delta_{m, r}(x)} \geq S_{c}$,

$14 m \in\{S C, C N G, L i, D i\}, i \in\{p k, o p\}, r \in\{e b, w b\}$;

15

16

17

18

19

20

21

22

23

$t_{3}=t_{a 3}+t_{c o 3}+t_{b 3}$

24

25

26

$t_{a 3}=\frac{v_{c, i}}{a_{v}}$

27

28

$29 t_{c o 3}=\frac{v_{c, i}-v_{c o}}{c_{v}}$

30

31

$32 t_{b 3}=\frac{v_{c o}}{d_{v}}$

33 with $i \in\{p k, o p\}$; speed $v_{c o}$ with deceleration rate $c_{v}\left(\mathrm{~km} / \mathrm{h}^{2}\right)$, and then braking regime is applied to reach the stop. Thus, we can determine the inter-stop travel time for each regime as follows:

Scenario 3: No cruising, $\frac{1}{\delta_{m r}(x)} \geq S_{c}$

Similarly, there are three intervals composed in this scenario: accelerating, coasting to 
$t_{m, r, i, 3}^{v}(x)=\left(v_{c, i} \cdot\left(\frac{1}{a_{v}}+\frac{1}{c_{v}}\right)+v_{c o, m, r, i}(x) \cdot\left(\frac{1}{d_{v}}-\frac{1}{c_{v}}\right)\right) \cdot \delta_{m, r}(x), \frac{1}{\delta_{m, r}(x)} \geq S_{c}$

$m \in\{S C, C N G, L i, D i\}, i \in\{p k, o p\}, r \in\{e b, w b\}$

$v_{c o, m, r, i}(x)=\sqrt{\frac{2 a_{v} \cdot d_{v} \cdot c_{v}-\left(a_{v}+c_{v}\right) \cdot v_{c, i}{ }^{2} \cdot d_{v} \cdot \delta_{m, r}(x)}{a_{v^{\prime}}\left(d_{v}-c_{v}\right) \cdot \delta_{m, r}(x)}}$,

$$
t_{4}=t_{a 4}+t_{c 4}+t_{c o 4}+t_{b 4}
$$

Thus, the per-kilometer travel time (hour) in this scenario is formulated as:

With $v_{c o, m, r, i}(x)$ (indicating the speed at the end of coasting with $i \in\{p k, o p\}, r \in\{e b, w b\}$, $m \in\{S C, C N G, L i, D i\}$, at point $x$ ) expressed as below, which is derived from the work of Vuchic (23):

$m \in\{S C, C N G, L i, D i\}, i \in\{p k, o p\}, r \in\{e b, w b\}$;

Scenario 4: With coasting and cruising, $\frac{1}{\delta_{m, r}(x)} \geq S_{c}$

In this scenario, buses can accelerate to cruising speed, then keep constant speed, coast from cruising speed, and brake. Thus, four intervals are included in the inter-stop travel time.

The distance for an inter-stop cruising is:

$S_{m}=\frac{1}{\delta_{m, r}(x)}-\left(\frac{v_{c, i}^{2}}{2 a_{v}}+\frac{v_{c, i}^{2}-v_{c o}^{2}}{2 c_{v}}+\frac{v_{c o}^{2}}{2 d_{v}}\right)$,

$m \in\{S C, C N G, L i, D i\}, i \in\{p k, o p\}, r \in\{e b, w b\}$;

We denote the inter-stop cruising time as $t_{c 4}$, and present it in the following equation: 
$1 \quad t_{c 4}=\frac{1}{\delta_{m, r}(x) \cdot v_{c, i}}-\frac{v_{c, i}}{2}\left(\frac{1}{a_{v}}+\frac{1}{c_{v}}\right)-\frac{v_{c o}^{2}}{2 v_{c, i}}\left(\frac{1}{d_{v}}-\frac{1}{c_{v}}\right)$

3

4

5

6

7

$8 \quad t_{4}=\frac{1}{\delta_{m, r}(x) \cdot v_{c, i}}+\left(\frac{1}{a_{v}}+\frac{1}{c_{v}}\right) \cdot \frac{v_{c, i}}{2}+\left(\frac{1}{c_{v}}-\frac{1}{d_{v}}\right) \cdot\left(\frac{v_{c o}^{2}}{2 v_{c, i}}-v_{c o}\right)$,

with $i \in\{p k, o p\}$;

10

11

12

13

14

15

$t_{m, r, i}^{v}(x)=t_{a, m, r, i}^{v}(x)+t_{c, m, r, i}^{v}(x)+t_{c o, m, r, i}^{v}(x)+t_{b, m, r, i}^{v}(x)$

19

20

21

22

23

$24 t_{a, m, r, i}^{v}(x)=\frac{v_{c, i} \cdot \delta_{m, r}(x)}{a_{v}}$

25

26

27

$$
t_{c o, m, r, i}^{v}(x)=\frac{v_{c, i}-v_{c o, m, r, i}(x)}{c_{v}} \cdot \delta_{m, r}(x)
$$

28

29

30

$$
t_{b, m, r, i}^{v}(x)=\frac{v_{c o, m, r, i}(x) \cdot \delta_{m, r}(x)}{d_{v}}
$$

31

32

$33 t_{c, m, r, i}^{v}(x)=\left[\frac{1}{\delta_{m, r}(x) \cdot v_{c, i}}-\frac{v_{c, i}}{2}\left(\frac{1}{a_{v}}+\frac{1}{c_{v}}\right)+\frac{v_{c o, m, r, i}^{2}(x)}{2 v_{c, i}}\left(\frac{1}{d_{v}}-\frac{1}{c_{v}}\right)\right] \cdot \delta_{m, r}(x)$ 
$t_{m, r, i}^{v}(x)=\left[\left(\frac{1}{c_{v}}-\frac{1}{d_{v}}\right) \cdot \frac{v_{c o, m, r, i}^{2}(x)}{2 v_{c, i}}-\left(\frac{1}{c_{v}}-\frac{1}{d_{v}}\right) \cdot v_{c o, m, r, i}(x)+\frac{1}{v_{c, i} \delta_{m, r}(x)}+\frac{v_{c, i}}{2 a_{v}}+\frac{v_{c, i}}{2 c_{v}}\right] \cdot \delta_{m, r}(x)$,

$m \in\{S C, C N G, L i, D i\}, i \in\{p k, o p\}, r \in\{e b, w b\}$

In scenario 2, which doesn't contain coasting regime, it means that the coasting speed equals to the cruising speed, $v_{c o, m, r, i}(x)=v_{c, i}$. Thus, Equation 17 can be converted into Equation 8. As for scenario 3 , which has no cruising regime, the cruising time is zero $\left(t_{c, m, r, i}^{v}(x)=0\right)$, and we can find the expression of $v_{c o, m, r, i}(x)$ the same as Equation 11. Scenario 1 is the combination of two conditions $\left(v_{c o, m, r, i}(x)=v_{c i}\right.$ and $\left.t_{c, m, r, i}^{v}(x)=0\right)$ and the Equation 6 can be yielded.

Therefore, Equation 17 is the generalized formula with four scenarios included. We can make an assumption that scenario 4 is conducted in every inter-stop trip. By plugging $v_{c o, m, r, i}(x)$ into optimization, we can finally yield the profile of $v_{c o, m, r, i}(x)$. Once we get the $v_{c o, m, r, i}(x)$ profile, the effect of coasting regime on operation cost can be explored.

After bus finishes its inter-stop travel, the bus dwell time will generate for passengers boarding and alighting and for opening and closing doors. Supposing that an onboard fare payment method is applied and one door is used for boarding and one or more doors are used for alighting, the dwell time at each stop is dominated by the process that takes longer. To facilate modeling, we convert dwell time at each stop to dwell time on per kilometer basis, denoted as $t_{m, r, i}^{d}(x)$. The expression of $t_{m, r, i}^{d}(x)$ is:

$$
t_{m, r, i}^{d}(x)=t_{d}(x) \cdot \delta_{m, r}(x)
$$

\section{Where}

$$
t_{d}(x)=t_{0}+\max \left(b o_{r, i}(x) \cdot h_{i} \cdot \frac{1}{\delta_{m, r}(x)} \cdot t_{b}, a l_{r, i}(x) \cdot h_{i} \cdot \frac{1}{\delta_{m, r}(x)} \cdot t_{a}\right)
$$

$m \in\{S C, C N G, L i, D i\}, i \in\{p k, o p\}, r \in\{e b, w b\}$

$t_{0}$ is the dead time for opening and closing doors, $t_{b}$ and $t_{a}$ are the average boarding and alighting time (hour) per passenger, respectively.

To summarize, the expression for in-vehicle cost is presented as follow: 
$1 \quad C_{v, m}=\sum_{r=e b, w b} \sum_{i=p k, o p} \int_{0}^{L} P_{r, i}(x) \cdot T_{i} \cdot\left(t_{m, r, i}^{v}(x)+t_{m, r, i}^{d}(x)\right) \cdot \theta_{v} d x$,

$2 m \in\{S C, C N G, L i, D i\}, i \in\{p k, o p\}, r \in\{e b, w b\}$;

$$
B_{h}=\frac{t_{p e a k}^{c}}{h_{p e a k}}
$$

$36 t_{i}^{c}=\sum_{r=e b, w b} \int_{0}^{L}\left(t_{m, r, i}^{v}(x)+t_{m, r, i}^{d}(x)\right) d x$,

Where $\{S C, C N G, L i, D i\}$; $\{S C, C N G, L i, D i\}$;

$\theta_{v}$ : the value of in-vehicle time (dollar per hour);

\section{Operator Cost} stops on the corridor is:

$$
C_{s, m}=\sum_{r=e b, w b} \int_{0}^{L}\left(\theta_{f}+\theta_{0} T\right) \cdot \delta_{m, r}(x) d x
$$

$$
m \in\{S C, C N G, L i, D i\}, r \in\{e b, w b\}
$$

$$
C_{f, m}^{f}=\theta_{b} \cdot B_{h}
$$

$m \in\{S C, C N G, L i, D i\}, i \in\{p k, o p\}, r \in\{e b, w b\}$

$P_{r, i}(x)$ : the number of passenger load at point $x$ in direction $r$, in period $i$ (passengers per hour);

$t_{m, r, i}^{v}(x)$ : bus's per-kilometer travel time (hour) with $r \in\{e b, w b\}, i \in\{p k, o p\}, m \in$

$t_{m, r, i}^{d}(x)$ : bus's per-kilometer dwell time (hour) with $r \in\{e b, w b\}, i \in\{p k, o p\}, m \in$

Each cost item in Equation $1 \mathrm{~b}$ will be discussed in this part. The cost for stop construction and maintenance is determined by $\theta_{f}$ and $\theta_{0}$, which represent the daily cost for stop construction (\$/day) and the hourly cost for stop maintenance (\$/hour), respectively. Thus, the per-day cost for

Where, $T$ presents the total operating time of a stop (hour).

The cost associated with fleet size is closely related to the maximum fleet size required, which is correspondent to peak hour fleet size, denoted as $B_{h} . B_{h}$ is determined as the quotient of peak hour cycle time $t_{\text {peak }}^{c}$ and peak hour headway $h_{\text {peak }}$. Thus: 
Where, $\theta_{b}$ is the fixed cost per bus (dollars per vehicle per day).

To determine the cost associated with driver wage, we suppose that a fixed wage $\theta_{h}$ is paid hourly for each on-duty hour, and the cost item for labor is expressed as:

$C_{f, m}^{h}=\theta_{h} \sum_{i=p k, o p} \frac{T_{i}}{h_{i}} \cdot t_{i}^{c}$,

$m \in\{S C, C N G, L i, D i\}, i \in\{p k, o p\}$;

Where $\theta_{h}$ is the hourly salary for driver (dollar per hour).

The cost associated with idling $C_{m f}^{d}$ is presented as:

$C_{f, m}^{d}=\theta_{d} \sum_{r=e b, w b} \sum_{i=p k, o p} \int_{0}^{L} \frac{T_{i}}{h_{i}} \cdot t_{m, r, i}^{d}(x) d x$,

$m \in\{S C, C N G, L i, D i\}, i \in\{p k, o p\}, r \in\{e b, w b\}$

Where $\theta_{d}$ is the per hour cost of idling per vehicle(dollar per vehicle per hour);

Then, we discuss the VKT related cost:

The cost associated with distance travelled by buses at cruising speed for daily bus flow is presented as the integral of the product of vehicle flow over day $\frac{T_{i}}{h_{i}}$, the per vehicle-kilometer cruising distance $t_{m, r, i, c}^{v}(x) \cdot v_{c, i}$, and the per vehicle-kilometer cost $\theta_{c}$. And the cost related is expressed as:

$C_{f, m}^{c}=\theta_{c} \sum_{r=e b, w b} \sum_{i=p k, o p} \int_{0}^{L} \frac{T_{i}}{h_{i}} \cdot t_{m, r, i, c}^{v}(x) \cdot v_{c, i} d x$,

$m \in\{S C, C N G, L i, D i\}, i \in\{p k, o p\}, r \in\{e b, w b\}$

Where, $\theta_{c}$ is the vehicle cost per unit distance covered at cruising speed (dollar per vehicle per kilometer).

Similarly, the cost associated with distance coasted $C_{f, m}^{c o}$, the cost associated with acceleration and deceleration $C_{f, m}^{a d}$ are expressed as follows, respectively:

$C_{f, m}^{c o}=\theta_{c o} \sum_{r=e b, w b} \sum_{i=p k, o p} \int_{0}^{L} \frac{T_{i}}{h_{i}} \cdot \frac{v_{c, i}^{2}-v_{c o, m, r, i}^{2}(x)}{2 c_{v}} \cdot \delta_{m, r}(x) d x$ 
$\min _{\delta_{m, r}(x), h_{i}, v_{c o, m, r, i}(x)}\left\{C_{u, m}+C_{o, m}+C_{P, m}\right\}$

Where (dollar per vehicle per kilometer);

\section{Pollutant Cost}

\section{Model Optimization}

$\theta_{c o}$ : the unit cost per kilometer traveled by coasting (dollar per vehicle per kilometer);

$\theta_{a d}$ : the unit cost per kilometer covered at accelerating from bus station or braking to bus station

In this model, we primarily take $\mathrm{HC}, \mathrm{CO}$, and $\mathrm{NO}_{\mathrm{x}}$ into account. The $n^{\text {th }}$ pollutant volume can be determined as the product of emission rate for pollutant $n\left(n=1: \mathrm{HC} ; n=2: \mathrm{CO} ; n=3\right.$ : $\left.\mathrm{NO}_{\mathrm{x}}\right)$ and the per-kilometer travel time of different driving regimes, as expressed below:

$$
P_{m, r, n}=e_{n}^{a} \cdot t_{a, m, r, i}^{v}(x)+e_{n}^{v} \cdot t_{c, m, r, i}^{v}(x)+e_{n}^{c o} \cdot t_{c o, m, r, i}^{v}(x)+e_{n}^{b} \cdot t_{b, m, r, i}^{v}(x)+e_{n}^{d} \cdot t_{m, r, i}^{d}(x),
$$

$m \in\{S C, C N G, L i, D i\}, i \in\{p k, o p\}, r \in\{e b, w b\}, n \in\{1,2,3\}$;

where $e_{n}^{a}, e_{n}^{v}, e_{n}^{c o}, e_{n}^{b}$, and $e_{n}^{d}$ represent the emission rates for pollutant $n$, under acceleration, cruising, coasting, deceleration, and standing regimes, respectively, in unit of (ton/hour).

Therefore, the pollutants cost generated while buses are operating on the corridor is:

$$
C_{P, m}=\sum_{n=1}^{3} \sum_{r=e b, w b} \sum_{i=p k, o p} \int_{0}^{L} P_{m, r, n} \cdot \theta_{p, n} \cdot \frac{T_{i}}{h_{i}} d x,
$$

$m \in\{S C, C N G, L i, D i\}, i \in\{p k, o p\}, r \in\{e b, w b\}, n \in\{1,2,3\}$

where, $\theta_{p, n}$ is the unit vehicle-related damage cost of pollutant (\$/ton).

In this model, the objective function is the generalized cost, which is the sum of user cost, operator cost, and pollutant cost. The expression of minimization problem is: 
1

$3\left\{\begin{array}{c}Q_{i} \leq \frac{c a p_{b u s}}{h_{i}} \\ \left(a l_{r, i}(x)+b o_{r, i}(x)\right) \cdot h_{i} \leq c a p_{s t o p} \cdot \delta_{m, r}(x) \\ 0 \leq h_{i}, 0 \leq \delta_{m, r}(x), 0 \leq v_{c o, m, r, i}(x) \leq v_{c, i}\end{array}\right.$

$$
m \in\{S C, C N G, L i, D i\}, i \in\{p k, o p\}, r \in\{e b, w b\}
$$
speed should be positive. that has $h_{i}$ variables. convergence is reached under constraints.

The first constraint indicates that the bus's capacity must feed the total passenger demand $(i \in\{p k, o p\})$. The second constraint is the stop capacity should satisfy the total demand of boarding and alighting. In addition, the optimal results of headway, stop density, and coasting

The objective function has three variables/functions: $\delta_{m, r}(x), h_{i}, v_{c o, m, r, i}(x)$, and the constrains are nonlinear. Those factors increase the complexity of the optimization. To obtain the analytical expression of each variable/function, two alternative procedures are proposed. Firstly, we introduced an initial value of headway to reduce the dimension. We can obtain the expression of coasting speed and stop density by solving first order condition $v_{c o, m, r, i}(x)^{*}=f\left(x, h_{i}\right)$ and $\delta_{m, r}^{*}(x)=f\left(x, h_{i}, v_{c o, m, r, i}(x)^{*}\right)$. Through this approach, the model is transformed into a problem

The second procedure contains two steps: in the first place, $\delta_{m, r}(x)$ and $v_{c o, m, r, i}(x)$ are replaced by the optimal expression $\delta_{m, r}^{*}(x)$ and $v_{c o, m, r, i}(x)^{*}$. As the optimal function of headway also contains stop density and coasting speed, which is $h_{i}^{*}=f\left(x, \delta_{m, r}(x)^{*}, v_{c o, m, r, i}(x)^{*}\right)$, the next step is to iterate the analytical expression of headway, stop density, and coasting speed until the

The first-order-condition expressions of stop density in each direction is:

$$
26 \delta_{m, r}(x)=\sqrt{\frac{\sum_{i=p k, o p}\left(a l_{r, i}(x)+b o_{r, i}(x)\right) \cdot T_{i} \cdot \theta_{a}}{4 v_{a}\left(\begin{array}{l}
f_{2, m, r, i}(x)+\sum_{i=p k, o p}\left[f_{3, m, r, i}(x)+\theta_{c} \cdot f_{4, m, r, i}(x)\right] \cdot \frac{T_{i}}{h_{i}} \\
+\sum_{n=1,2,3} \sum_{i=p k, o p} \frac{\theta_{p, n} \cdot T_{i}}{h_{i}} \cdot\left(f_{5, m, r, i}(x)+\frac{e_{n}^{v}}{v_{c, i}} \cdot f_{4, m, r, i}(x)\right)
\end{array}\right)}}
$$

$m \in\{S C, C N G, L i, D i\}, i \in\{p k, o p\}, r \in\{e b, w b\}, n \in\{1,2,3\}$;

Where

$$
f_{1, m, r, i}(x)=\left(\frac{1}{c_{v}}-\frac{1}{d_{v}}\right) \cdot \frac{v_{c o, m, r, i}^{2}(x)}{2 v_{c, i}}-\left(\frac{1}{c_{v}}-\frac{1}{d_{v}}\right) \cdot v_{c o, m, r, i}(x)+\frac{v_{c, i}}{2 a_{v}}+\frac{v_{c, i}}{2 c_{v}}
$$




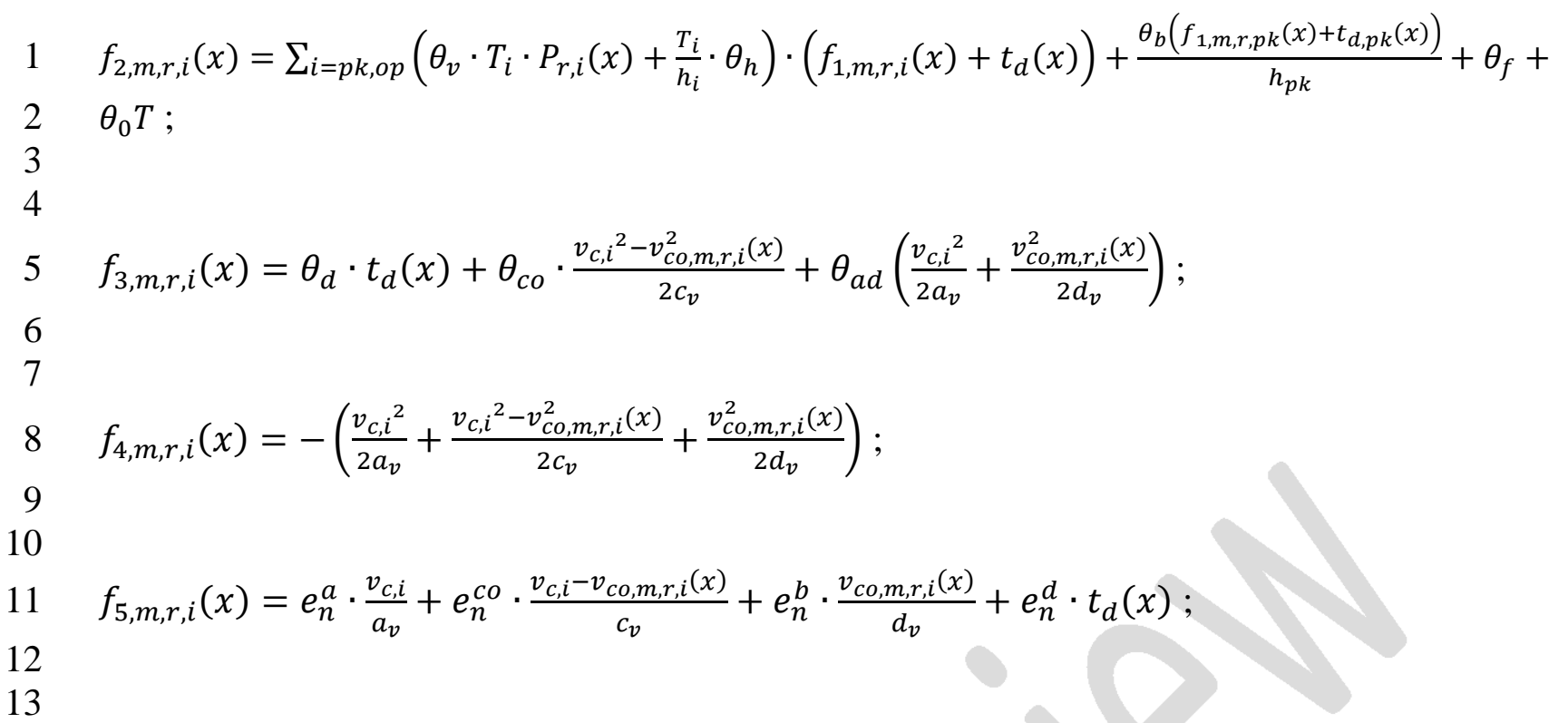

It should be mentioned that the stop density function is different on two sides of corridor to reflect the flexibility of locating curbside bus stops.

The expressions of optimal headway in peak hour and off-peak hour are as follows, respectively:

$23 h_{o p}=\sqrt{\frac{\sum_{r=e b, w b} \int_{0}^{L}\left[\theta_{h} \cdot T_{o p} \cdot\left(t_{m, r, o p}^{v}(x)+t_{m, r o p}^{d}(x)\right)+g_{1, m, r, o p}(x)+\sum_{n=1}^{3} T_{o p} \cdot \theta_{p, n} \cdot P_{m, r, n}(x)\right] d x}{\sum_{r=e b, w b} \int_{0}^{L} b o_{r, o p}(x) \cdot \frac{T_{o p}}{2} \cdot \theta_{w}+P_{r, o p}(x) \cdot T_{o p} \cdot g_{2, m, r, o p}(x) \cdot \theta_{v} d x}}$

$m \in\{S C, C N G, L i, D i\}, r \in\{e b, w b\}, n \in\{1,2,3\} ;$

Where

$g_{1, m, r, i}(x)=T_{i} \cdot \theta_{c} \cdot t_{c, m, r, i}^{v}(x) \cdot v_{c, i}+\theta_{a d} \cdot\left(\frac{v_{c, i}{ }^{2}}{2 a_{v}}+\frac{v_{c,, m, r}^{2}(x)}{2 d_{v}}\right) \cdot \delta_{m, r}(x) \cdot T_{i}+T_{i} \cdot \theta_{d} \cdot t_{m, r, i}^{d}(x)+T_{i}$.

$\theta_{c o} \cdot \frac{v_{c, i}{ }^{2}-v_{c, m, r, i}^{2}(x)}{2 c_{v}} \cdot \delta_{m, r}(x)$;

$$
g_{2, m, r, i}(x)=\max \left(b o_{r i}(x) \cdot t_{m}^{b}, a l_{r i}(x) \cdot t_{m}^{a}\right)
$$




$$
\delta_{m, r}(x)=\sqrt{\frac{\sum_{i=p k, o p}\left(a l_{r, i}(x)+b o_{r, i}(x)\right) \cdot T_{i} \cdot \theta_{a}}{4 v_{a}\left(f_{2, m, r, i}(x)+\sum_{i=p k, o p}\left[f_{3, m, r, i}(x)+\theta_{c} \cdot f_{4, m, r, i}(x)\right] \cdot \frac{T_{i}}{h_{i}}\right)}}
$$

$v_{c o, m, r, i}(x)=\operatorname{mid}\left(0, \tilde{v}_{c o, m, r, i}(x), v_{c, i}\right)$

$m \in\{S C, C N G, L i, D i\}, i \in\{p k, o p\}, r \in\{e b, w b\}, n \in\{1,2,3\}$ where function $\operatorname{mid}(x, y, z)$ return the middle value among $x, y$, and $z$.

As for supercharge bus and Lithium-ion bus, the pollutant emitted can be neglected, so the optimal expressions of stop density, headway, and coasting speed are simplified as follows:

$m \in\{S C, C N G, L i, D i\}, i \in\{p k, o p\}, r \in\{e b, w b\}, n \in\{1,2,3\}$;

Where $u_{r, i}(x)=\theta_{v} \cdot T_{i} \cdot P_{r, i}(x)+\frac{\theta_{b}}{h_{p k}}+\theta_{h} \cdot \frac{T_{i}}{h_{i}}$

$v_{c o, m, r, i}(x)$ is given by:

Once the optimal value of headway is obtained, we can determine $v_{c o, m, r, i}(x)$. The first order condition is applied to obtain the unconstrained optimal $\tilde{v}_{c o, m, r, i}(x)$ as follows:

$\tilde{v}_{c o, m, r, i}(x)=\frac{\left(\frac{1}{c_{v}}-\frac{1}{d_{v}}\right) \cdot u_{r, i}(x)+\sum_{n=1}^{3} \frac{T_{i}}{h_{i}} \cdot \theta_{p, n} \cdot\left(\frac{e_{n}^{c o}}{c_{v}}-\frac{e_{n}^{b}}{d_{v}}\right)}{\left(\frac{1}{c_{v}}-\frac{1}{d_{v}}\right) \cdot\left[\frac{u_{r, i}(x)}{v_{c, i}}+\frac{T_{i}}{h_{i}} \cdot\left(\theta_{c}-\theta_{c o}+\theta_{a d}+\sum_{n=1}^{3} \frac{e_{n}^{v}}{v_{c, i}} \cdot \theta_{p, n}\right)\right]}$

$26 \quad h_{p k}=\sqrt{\frac{\sum_{r=e b, w b} \int_{0}^{L}\left[\left(\theta_{b}+\theta_{h} \cdot T_{p k}\right)\left(t_{m, r, o p}^{v}(x)+t_{m, r, o p}^{d}(x)\right)+g_{1, m, r, p k}(x)\right] d x}{\sum_{r=e b, w b} \int_{0}^{L} b o_{r, p k}(x) \cdot \frac{T}{2} \cdot \theta_{w}+P_{r, p k}(x) \cdot T_{p k} \cdot g_{2, m, r, p k}(x) \cdot \theta_{v} d x}}$, 
$2 \quad \tilde{v}_{c o, m, r, i}(x)=\frac{u_{r, i}(x)}{\frac{u_{r, i}(x)}{v_{c, i}}+\frac{T_{i}}{h_{i}} \cdot\left(\theta_{c}-\theta_{c o}+\theta_{a d}\right)}$

3

4

$v_{c o, m, r, i}(x)=\operatorname{mid}\left(0, \tilde{v}_{c o, m, r, i}(x), v_{c, i}\right)$,

$m \in\{S C, C N G, L i, D i\}, i \in\{p k, o p\}, r \in\{e b, w b\}, n \in\{1,2,3\}$;

\section{NUMERICAL APPLICATION}

\section{System Inputs}

In this section, we apply continuum model to the $7^{\text {th }}$ bus route, Yaan (City), China, where the first supercharge bus route is in operation. The studied corridor is approximately $11 \mathrm{~km}$ in length, 21 stops in the east direction and 22 stops in the west, as shown in Figure 1. The bus's peak-hour cruising speed and off-peak hour cruising speed are given by Shu Tong Transportation Agency. All the operator cost items are shown in Table 1 as follows:

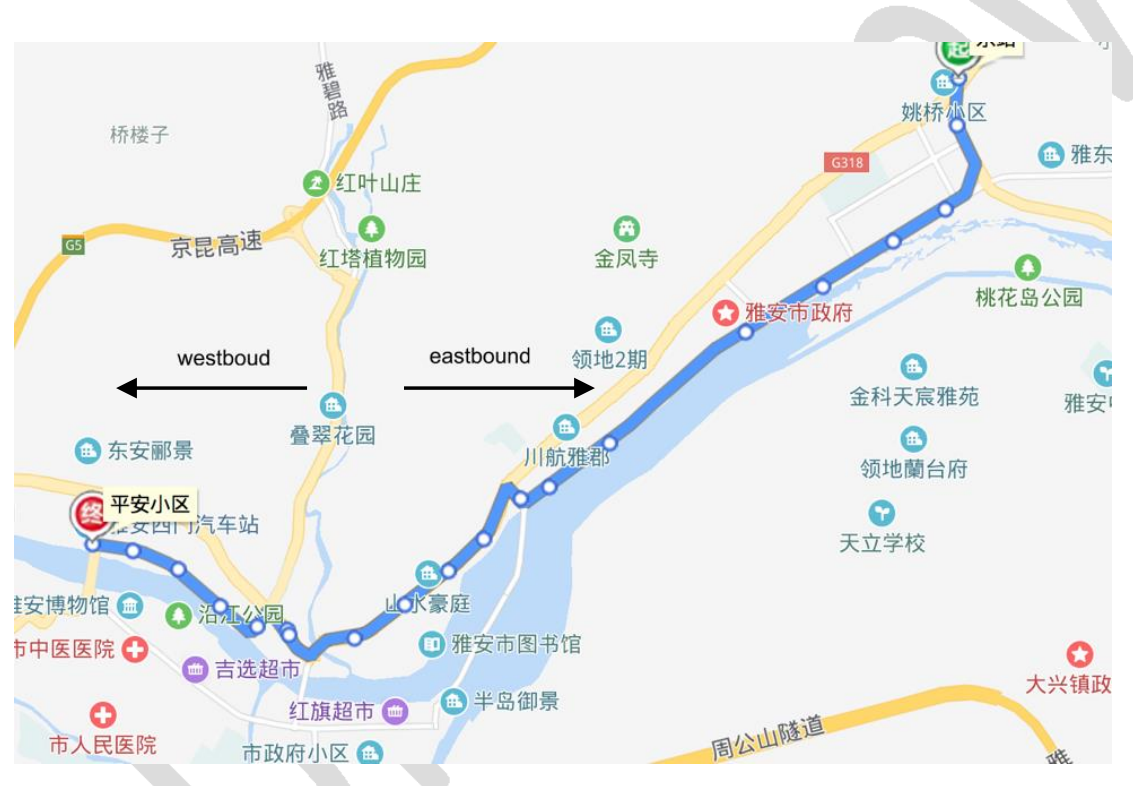

FIGURE 1 The No.7 bus route, Yaan (China)

TABLE 1 Cost Parameters of Four Transit Modes

\begin{tabular}{|l|l|l|}
\hline \multicolumn{3}{|c|}{ Supercharge Cost Parameters } \\
\hline Parameters & Value & Source \\
\hline $\begin{array}{l}\text { \$I-S infrastructure stop cost } \\
(\$ / \text { stop/h) }\end{array}$ & $\$ 0.47$ & $\begin{array}{l}\text { Derived from Gu et al (2016), with additional } \\
\text { construction cost 2,590,000 yuan for charging } \\
\text { facilities. }\end{array}$ \\
\hline
\end{tabular}




\begin{tabular}{|c|c|c|}
\hline \multicolumn{3}{|l|}{ Operating Costs (Distance) } \\
\hline Maintenance cost per veh-km & $\$ 0.012$ & Shu Tong Transpotation Agency \\
\hline Energy cost per $\mathrm{km}(\$ / \mathrm{km})$ & $\$ 0.088$ & Electricity price 2018 \\
\hline \$v, Cost per veh-km (\$/veh-km) & $\$ 0.1$ & \\
\hline \multicolumn{3}{|l|}{ Operating Costs (Time) } \\
\hline Employees per vehicle & 1.5 & \\
\hline Average wage $(\$ / \mathrm{h})$ & $\$ 6.15$ & Yaan City average wage standard \\
\hline Labour cost per hour & $\$ 9.225$ & \\
\hline Vehicle cost $(\$)$ & $\$ 257,353$ & \\
\hline Vehicle lifespan (years) & 8 & \\
\hline Depreciation cost per hr $(\$ / \mathrm{hr})$ & $\$ 6.3$ & $\begin{array}{l}\text { Assumed straight-line depreciation, work } 14 \mathrm{hr} \\
\text { per day }\end{array}$ \\
\hline \multicolumn{3}{|c|}{ CNG Cost Parameters } \\
\hline Parameters & \begin{tabular}{|l|} 
Value \\
\end{tabular} & $\infty \times$ \\
\hline $\begin{array}{l}\text { \$I-S infrastructure stop cost } \\
(\$ / \mathrm{stop} / \mathrm{h})\end{array}$ & $\$ 0.35$ & Derived from Gu et al (2016) \\
\hline \multicolumn{3}{|l|}{ Operating Costs (Distance) } \\
\hline Maintenance cost per veh-km & $\$ 0.02$ & Shu Tong Transpotation Agency \\
\hline Energy cost per km $(\$ / \mathrm{km})$ & $\$ 0.238$ & CNG price 2018 \\
\hline \$v, Cost per veh-km (\$/veh-km) & $\$ 0.258$ & \\
\hline \multicolumn{3}{|l|}{ Operating Costs (Time) } \\
\hline Employees per vehicle & 2 & + \\
\hline Average wage $(\$ / \mathrm{hr})$ & $\$ 6.15$ & Yaan City average wage standard \\
\hline Labor cost per hour & $\$ 12.3$ & \\
\hline Vehicle cost $(\$)$ & $\$ 73,529$ & \\
\hline \multicolumn{3}{|l|}{ Vehicle lifespan (years) } \\
\hline Depreciation cost per $\mathrm{hr}(\$ / \mathrm{hr})$ & $\$ 1.8$ & $\begin{array}{l}\text { Assumed straight-line depreciation, work } 14 \mathrm{hr} \\
\text { per day }\end{array}$ \\
\hline \multicolumn{3}{|c|}{\begin{tabular}{|l|l|} 
Lithium-ion battery Bus Cost Parameters \\
\end{tabular}} \\
\hline Parameters $>$ & Value & Source \\
\hline $\begin{array}{l}\text { \$I-S infrastructure stop cost } \\
(\$ / \text { stop } / \mathrm{h})\end{array}$ & $\$ 0.58$ & $\begin{array}{l}\text { Derived from } \mathrm{Gu} \text { et al (2016), with an } \\
\text { additional cost 5,000,000yuan for supplement } \\
\text { equipment }\end{array}$ \\
\hline \multicolumn{3}{|l|}{ Operating Costs (Distance) } \\
\hline Maintenance cost per veh-km & $\$ 0.242$ & Shu Tong Transpotation Agency \\
\hline Energy cost per $\mathrm{km}(\$ / \mathrm{km})$ & $\$ 0.088$ & Electricity price 2018 \\
\hline$\$ \mathrm{v}$, Cost per veh-km (\$/veh-km) & $\$ 0.33$ & \\
\hline \multicolumn{3}{|l|}{ Operating Costs (Time) } \\
\hline Employees per vehicle & 1.7 & \\
\hline Average wage $(\$ / \mathrm{hr})$ & $\$ 6.15$ & Yaan City average wage standard \\
\hline Labour cost per hour & $\$ 10.455$ & \\
\hline Vehicle cost $(\$)$ & $\$ 235,294$ & \\
\hline Vehicle lifespan (years) & 8 & \\
\hline
\end{tabular}




\begin{tabular}{|c|c|c|}
\hline Depreciation cost per hr $(\$ / \mathrm{hr})$ & $\$ 5.76$ & $\begin{array}{l}\text { Assumed straight-line depreciation, work } 14 \mathrm{hr} \\
\text { per day }\end{array}$ \\
\hline \multicolumn{3}{|c|}{ Diesel Bus Cost Parameters } \\
\hline Parameters & Value & Source \\
\hline $\begin{array}{l}\text { \$I-S infrastructure stop cost } \\
(\$ / \text { stop/h) }\end{array}$ & $\$ 0.35$ & Derived from Gu et al (2016) \\
\hline \multicolumn{3}{|l|}{ Operating Costs (Distance) } \\
\hline Maintenance cost per veh-km & $\$ 0.025$ & Shu Tong Transpotation Agency \\
\hline Energy cost per $\mathrm{km}(\$ / \mathrm{km})$ & $\$ 0.512$ & Diesel price 2018 \\
\hline$\$ v$, Cost per veh-km (\$/veh-km) & $\$ 0.537$ & \\
\hline \multicolumn{3}{|l|}{ Operating Costs (Time) } \\
\hline Employees per vehicle & 2 & \\
\hline Average wage $(\$ / \mathrm{hr})$ & $\$ 6.15$ & Yaan City average wage standard \\
\hline Labor cost per hour & $\$ 12.3$ & \\
\hline Vehicle cost $(\$)$ & $\$ 73,529$ & 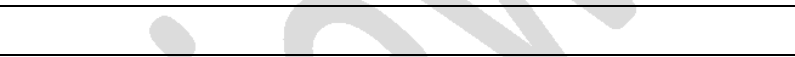 \\
\hline Vehicle lifespan (years) & 8 & 3 \\
\hline Depreciation cost per $\mathrm{hr}(\$ / \mathrm{hr})$ & $\$ 1.8$ & $\begin{array}{l}\text { Assumed straight-line depreciation, work } 14 \mathrm{hr} \\
\text { per day }\end{array}$ \\
\hline
\end{tabular}

In this analysis, four different vehicle types are considered, among which two of them are clean-energy bus (i.e., supercharge bus and Lithium-ion bus), the others are conventional buses (i.e., CNG buses and diesel buses). It should be mentioned that all the vehicles are $12 \mathrm{~m}$ in length. The emission standard for CNG bus and Diesel bus is both of China National IV standard. The emission rates of conventional buses at different driving regimes are given in Table 2, the data is adopted from previous studies (24-25) and is summarized below.

TABLE 2 Emission Rates of Pollutants at Different Driving Cycles

\begin{tabular}{|c|c|c|c|c|}
\hline \multicolumn{5}{|c|}{ 12m China National IV CNG bus } \\
\hline Pollutant & Idling & Acceleration & Deceleration & Constant velocity \\
\hline$N O_{X}(\mathrm{~g} / \mathrm{s})$ & 0.0036 & 0.0152 & 0.0071 & 0.0115 \\
\hline $\mathrm{HC}(\mathrm{g} / \mathrm{s})$ & 0.0012 & 0.0034 & 0.0021 & 0.0027 \\
\hline $\mathrm{CO}(\mathrm{g} / \mathrm{s})$ & 0.0211 & 0.0473 & 0.0303 & 0.0363 \\
\hline \multicolumn{5}{|c|}{ 12m China National IV Diesel Bus } \\
\hline$N O_{X}(\mathrm{~g} / \mathrm{s})$ & 0.0226 & 0.0973 & 0.0503 & 0.0766 \\
\hline HC $(g / s)$ & 0.0013 & 0.0022 & 0.0014 & 0.0018 \\
\hline $\mathrm{CO}(\mathrm{g} / \mathrm{s})$ & 0.0070 & 0.0212 & 0.0069 & 0.0137 \\
\hline
\end{tabular}

The boarding and alighting density function is obtained by using the on and off data which is collected on $6^{\text {th }}$ April, 2017 by Shu Tong Transportation Agency. All the programming process is performed on Matlab platform. Figure 2 shows the boarding and alighting densities along the corridor in terms of different time periods (i.e., peak hour and off-peak hour). 

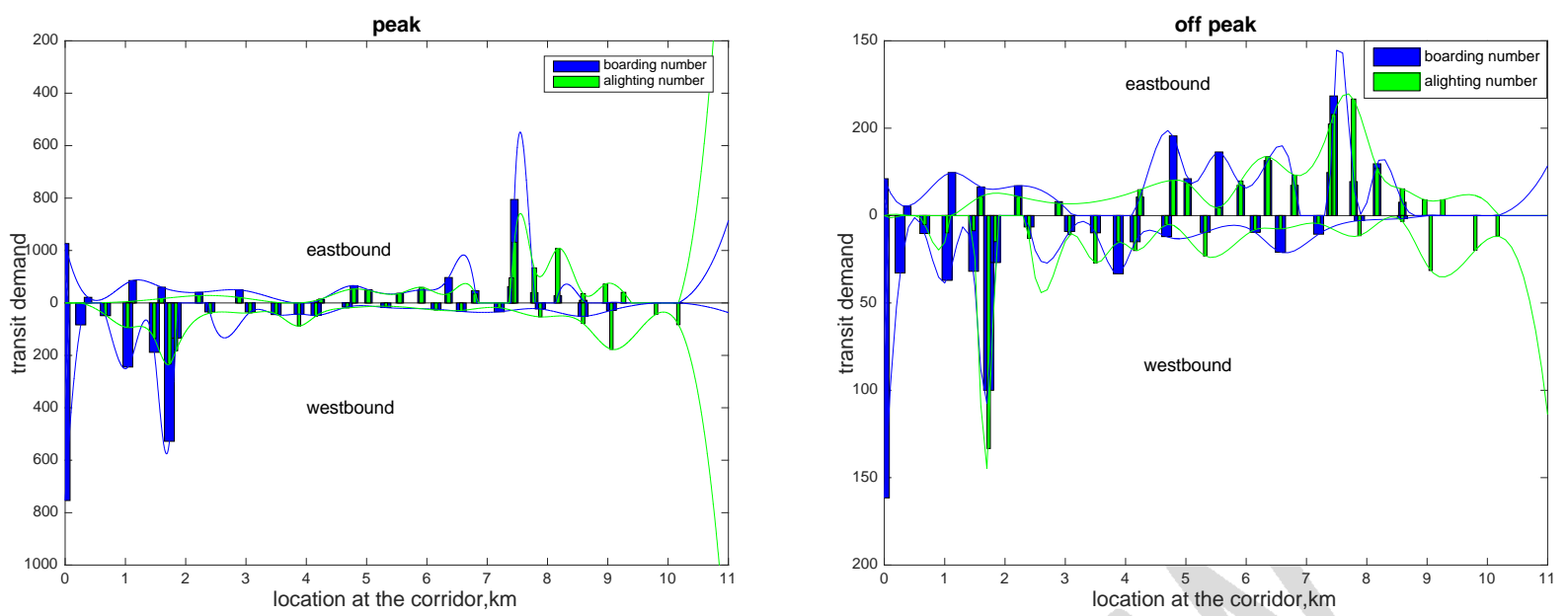

FIGURE 2 Boarding and alighting densities along the corridor in different time periods

The values of walking time, riding time, and waiting time are derived from (16), and are set at $4.09 \$ /$ hour, $1.64 \$ /$ hour, $2.73 \$ /$ hour, respectively. Passengers access/egress bus stop at $3.6 \mathrm{~km} / \mathrm{h}$. The time for opening and closing doors is $2 \mathrm{~s}$ at each stop. According to the schedule provided by Shu Tong Transportation Agency, in the day time, from 7:00 to 17:00, the headway in current system is $7 \mathrm{~min}$; and during the evening peak, which is 17:00-19:00, the service headway is 12min; for 19:00-20:00, the service headway is $15 \mathrm{~min}$; 20:00-21:00, the service headway prolonged to $20 \mathrm{~min}$.

\section{Optimal Design Solution Analysis}

13 Figure 3 presents the discretization of the bi-directional stop density functions for four transit modes. We discretize the bi-directional stop density functions by locating stops when the integral of its left boundary and right boundary is 1 . Here, we take the center line of each stop spacing as the left/right boundary. The detailed description of the discretization method is derived from (16). In the Figure, the circles on the stop density curves represent the optimal location of stops and the dash lines represent the boundaries of each stop coverage market. The system characteristics of current and optimized $7^{\text {th }}$ route in Yaan (City) are summarized in Table 3. 

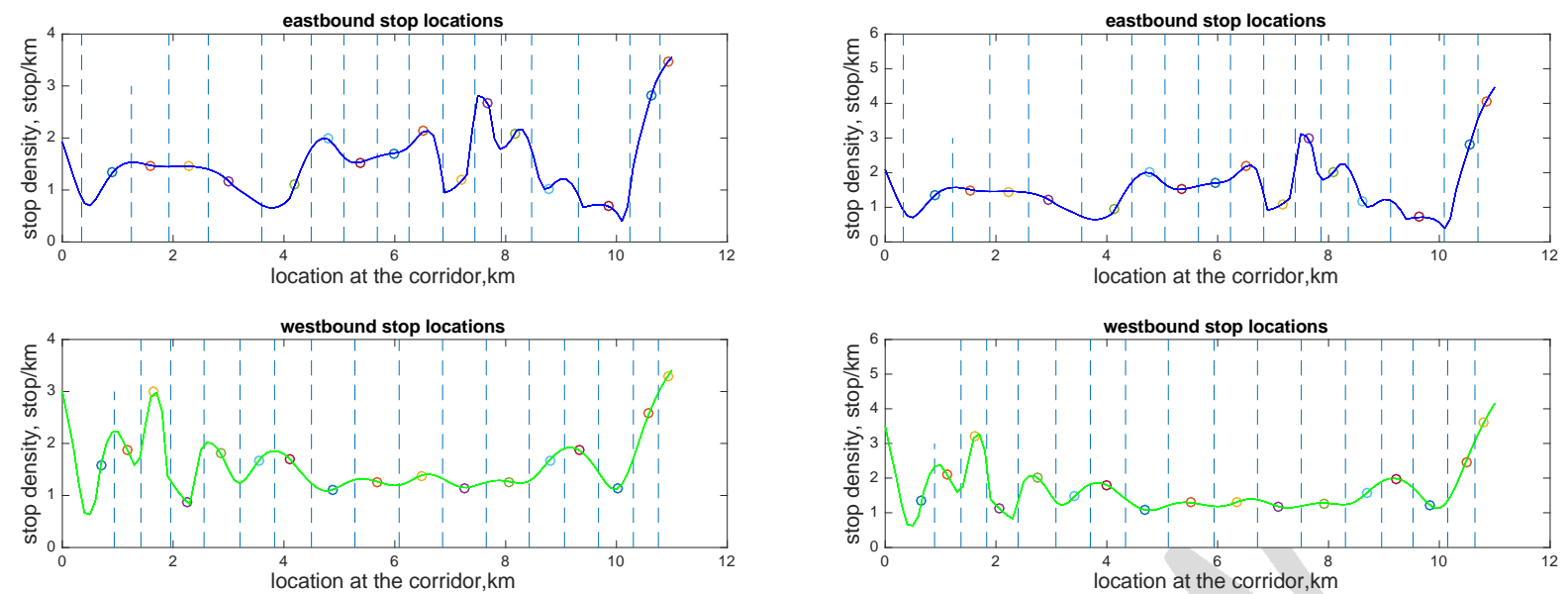

(a) Supercharge bus stop locations

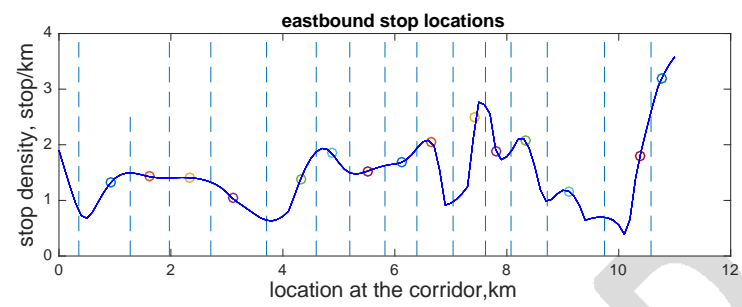

(b) CNG bus stop loactions

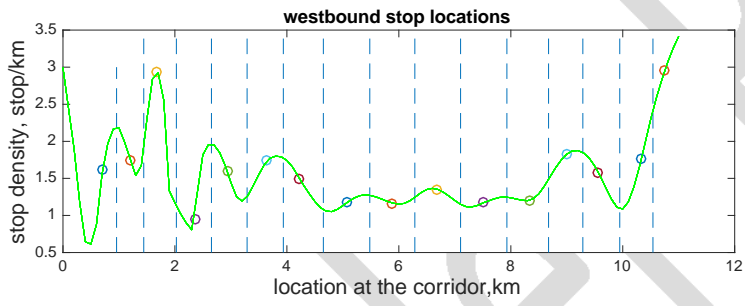

(c) Li-thium-ion bus stop locations
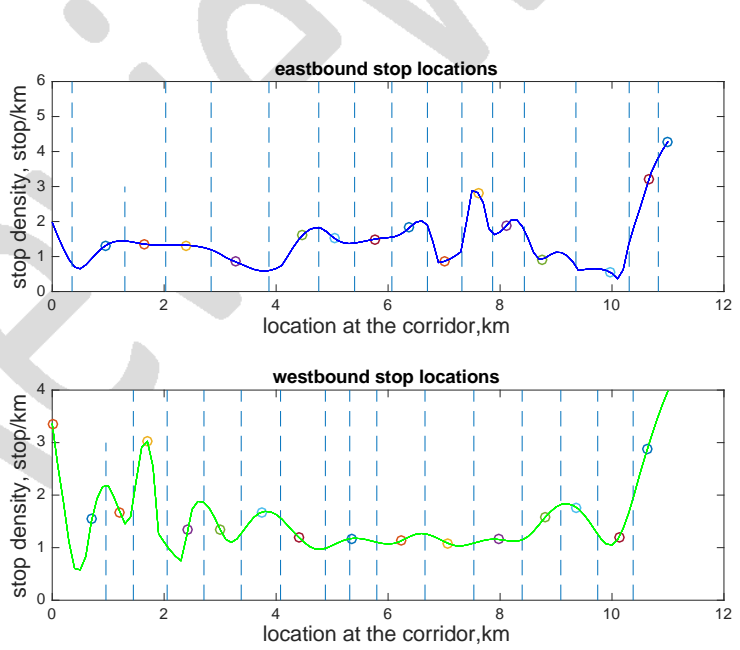

(d) Diesel bus stop locations

\section{FIGURE 3 Optimal stop locations}

In Table 3, we compare the optimal system costs of four vehicle types. The optimal results indicate that when $\mathrm{CNG}$ buses are operating on the route, the system cost is the lowest. Note that the cost gap between CNG buses system and supercharge buses system is slight (8080.9\$/day vs. $8127.4 \$$ day). Then, we discretize the optimal results based on CA approach and we obtain the real results when CA models are applied practically, which are shown in the third row. Comparing with the optimal results with discretized results, the outcomes of discrete models are in neighborhood with that of CA models, with error less than 3\%. In other words, if we employ the discretized results on a real bus route, the system cost will be closed to optimal value, which verified the applicability and accuracy of CA models. Finally, we compare the current system costs (detailed in user cost, operator cost, and pollutant cost for conventional buses), with optimal results and discretized results. Remarkably, the optimal results have saved more than $50 \%$ of the system cost, especially in user cost. 
In terms of system design, comparing with the current route configuration, the average stop spacing is increased by up to $31.3 \%$. As for the service headway, the optimal headway in peak hour is ranging from $6.55 \mathrm{~min}$ to $8.30 \mathrm{~min}$ with respect to vehicle type. Among them, CNG is the most frequently emited bus type. According to optimal design, the optimal headway in peak hour has been decreased by up to $31 \%$, while in off-peak hour, the optimal headways are approximately equal to the observed values in current system.

TABLE 3 System Characteristics of Current and Optimized $7^{\text {th }}$ route in Yaan

\begin{tabular}{|c|c|c|c|}
\hline \multicolumn{4}{|c|}{ Supercharge Bus Route Design } \\
\hline System metrics & Current corridor & Optimal results & Real results \\
\hline$h_{\text {peak }}, \min$ & 9.50 (weighted) & 7.76 & 7.76 \\
\hline$h_{\text {off-peak }}, \min$ & 9.64 (weighted) & 8.12 & 8.12 \\
\hline Spacing $_{e b}, \mathrm{~km}$ & 0.52 & 0.65 (17 stops) & 0.65 \\
\hline $\operatorname{Spacing}_{w b}, \mathrm{~km}$ & 0.55 & 0.61 (18 stops) & 0.61 \\
\hline$C_{u}, \$ /$ day & $14,081.0$ & $5,567.4$ & $5,540.5$ \\
\hline$C_{O}, \$ /$ day & $2,624.2$ & $2,559.9$ & $2,359.4$ \\
\hline$T C, \$$ day & $16,706.2$ & $8,127.3$ & $7,899.9$ \\
\hline Cost Saving, $\%$ & na & $51.3 \%$ & $52.7 \%$ \\
\hline $\begin{array}{l}\text { Difference \% (CA and } \\
\text { discrete models) }\end{array}$ & na & $2.8 \%$ & \\
\hline \multicolumn{4}{|c|}{ CNG Bus Route Design } \\
\hline System metrics & Current corridor & \begin{tabular}{|l|} 
Optimal results \\
\end{tabular} & Real results \\
\hline$h_{\text {peak }}, \min$ & 9.50 (weighted) & 6.55 & 6.55 \\
\hline$h_{o f f-p e a k}, \min$ & 9.64 (weighted) & 10.68 & 10.68 \\
\hline Spacing $_{e b}, \mathrm{~km}$ & 0.52 & 0.65 (17 stops) & 0.65 (17 stops) \\
\hline $\operatorname{Spacing}_{w b}, \mathrm{~km}$ & 0.55 & 0.61 (18 stops) & 0.61 (18 stops) \\
\hline$C_{u}, \$ /$ day & $15,365.0$ & $5,594.7$ & $5,796.2$ \\
\hline$C_{O}$, \$/day & $2,165 \longrightarrow$ & $2,398.2$ & $2,412.7$ \\
\hline$C_{P}, \$ /$ day & 252.1 & 88.0 & 91.3 \\
\hline$T C, \$ /$ day & $17,782.1$ & $8,080.9$ & $8,300.2$ \\
\hline Cost Saving, \% & na & $54.6 \%$ & $53.3 \%$ \\
\hline $\begin{array}{l}\text { Difference } \% \text { (CA and } \\
\text { discrete models) }\end{array}$ & na & $2.7 \%$ & \\
\hline \multicolumn{4}{|c|}{ Lithium-ion Battery Bus Route Design } \\
\hline System metrics & Current corridor & Optimal results & Real results \\
\hline$h_{\text {peak }}, \min$ & 9.50 (weighted) & 8.3 & 8.3 \\
\hline$h_{o f f-p e a k}, \min$ & 9.64 (weighted) & 10.3 & 10.3 \\
\hline Spacing $_{e b}, \mathrm{~km}$ & 0.52 & 0.69 (16 stops) & 0.69 (16 stops) \\
\hline $\operatorname{Spacing}_{w b}, \mathrm{~km}$ & 0.55 & 0.65 (17 stops) & 0.65 (17 stops) \\
\hline$C_{u}, \$ /$ day & $14,320.0$ & $5,911.1$ & $6,054.6$ \\
\hline$C_{O}, \$ /$ day & $3,223.1$ & $2,818.0$ & $2,880.2$ \\
\hline$T C, \$ /$ day & $17,543.1$ & $8,729.1$ & $8,934.8$ \\
\hline Cost Saving, $\%$ & na & $50.2 \%$ & $47.8 \%$ \\
\hline
\end{tabular}




\begin{tabular}{|c|c|c|c|}
\hline Difference\% (CA and & na & \multicolumn{2}{|l|}{$2.3 \%$} \\
\hline \multicolumn{4}{|c|}{ Diesel Bus Route Design } \\
\hline System metrics & Current corridor & Optimal results & Real results \\
\hline$h_{\text {peak }}, \min$ & 9.50 (weighted) & 7.60 & 7.60 \\
\hline$h_{o f f-\text { peak }}, \min$ & 9.64 (weighted) & 12.89 & 12.89 \\
\hline Spacing $_{e b}, \mathrm{~km}$ & 0.52 & 0.69 (16 stops) & 0.69 (16 stops) \\
\hline Spacing $_{w b}, \mathrm{~km}$ & 0.55 & 0.65 (17 stops) & 0.65 (17 stops) \\
\hline$C_{u}, \$ /$ day & $16,130.0$ & $6,305.8$ & $6,146.9$ \\
\hline$C_{O}, \$ /$ day & $2,542.2$ & $2,688.9$ & $2,534.7$ \\
\hline$C_{P}, \$ /$ day & 248.9 & 62.5 & 106.5 \\
\hline$T C, \$ /$ day & $18,921.1$ & $9,057.2$ & $8,788.1$ \\
\hline Cost Saving, \% & na & $52.1 \%$ & $53.6 \%$ \\
\hline $\begin{array}{l}\text { Difference\% (CA and } \\
\text { discrete models) }\end{array}$ & na & $3 \%$ & \\
\hline
\end{tabular}

The Effect of Coasting Regime

Previously, we have discussed the optimal values of stop density functions, service headways (peak and off-peak hour), and system costs for different bus types. This part will focus on analyzing the optimal value of coasting speed in different periods (peak hour and off-peak hour) for four vehicle types and investigating the interrelationship of coasting regime on system cost. The obtimized profiles of coasting speed with respect to different vehicle types in peak/off-peak hours are presented as follows in Figure 4,5, respectively.

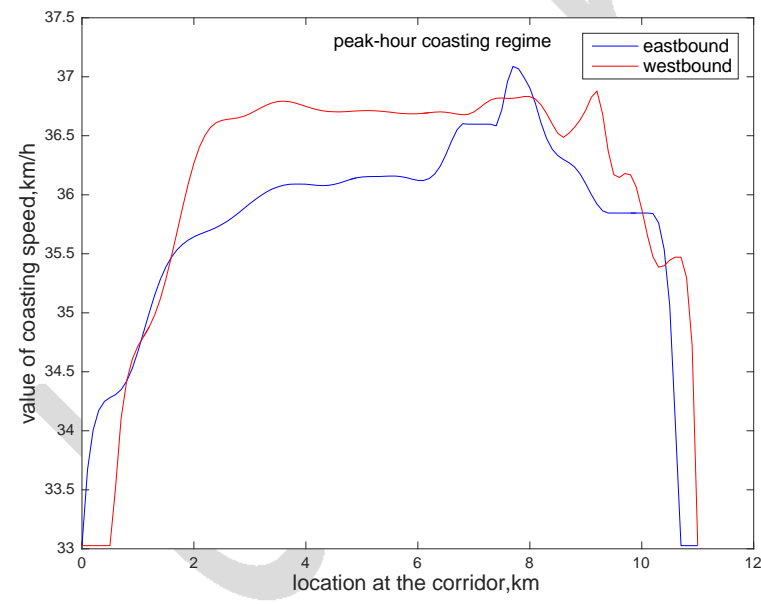

(a) Supercharge bus coasting profile

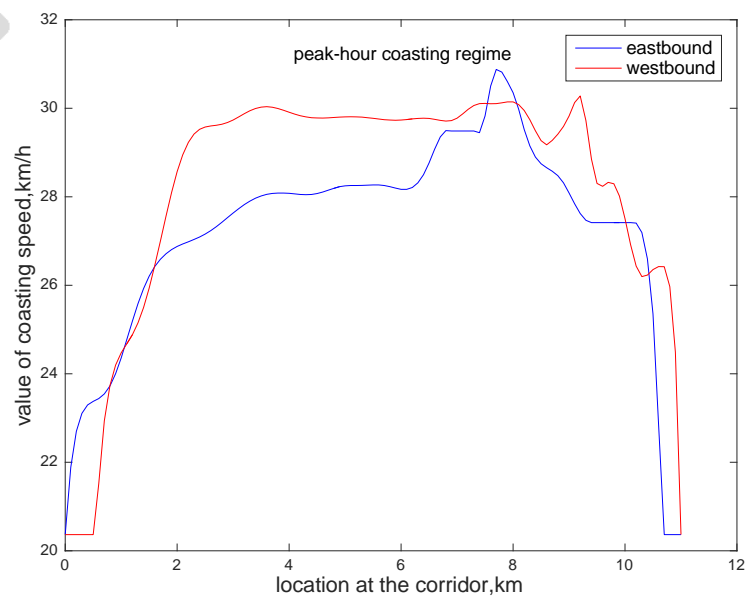

(b) $\mathrm{CNG}$ bus coasting profile 


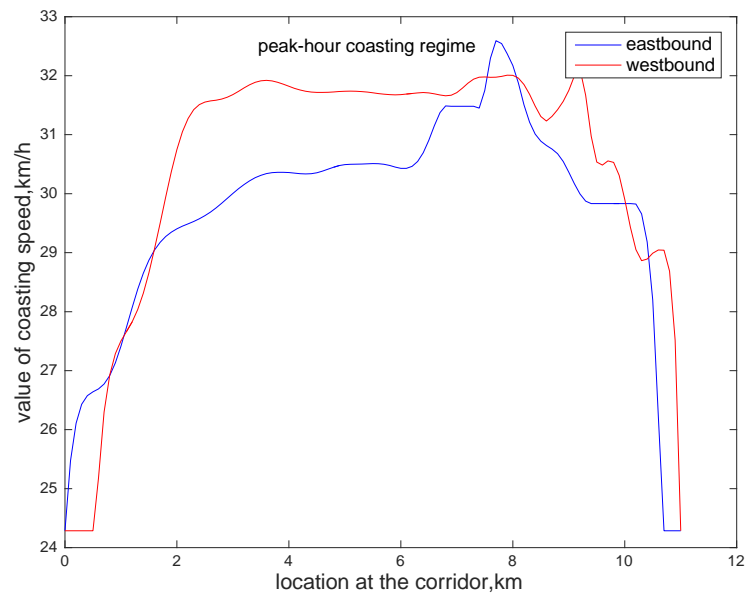

(c) Lithium-ion bus coasting profile

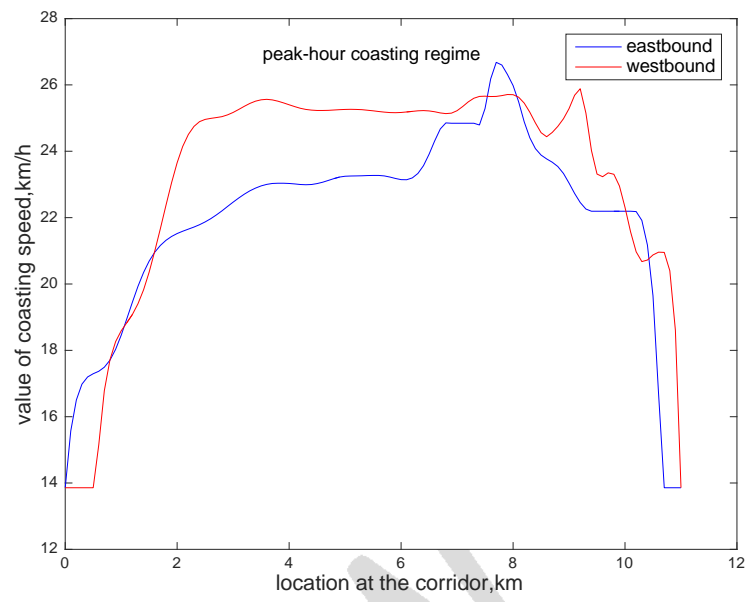

(d) Diesel bus coasting profile

\section{FIGURE 4 Coasting speed profiles in peak hours for four vehicle types}

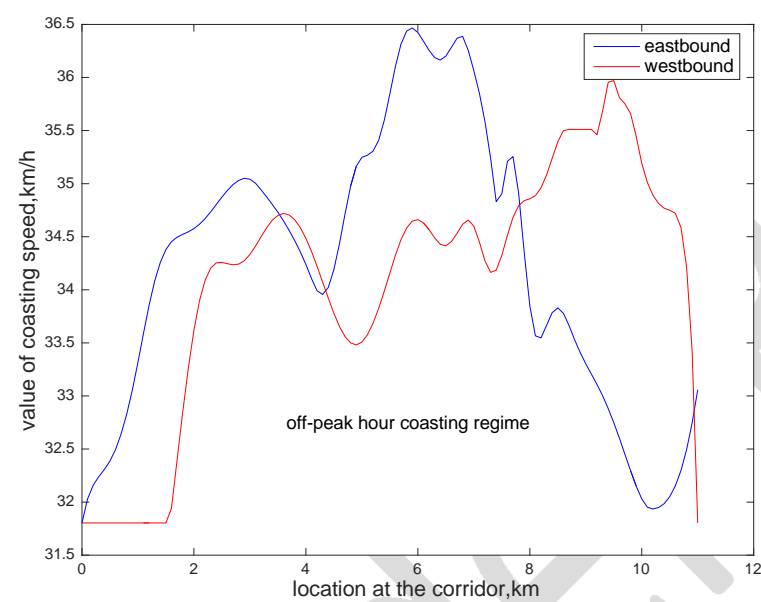

(a) Supercharge bus coasting profile

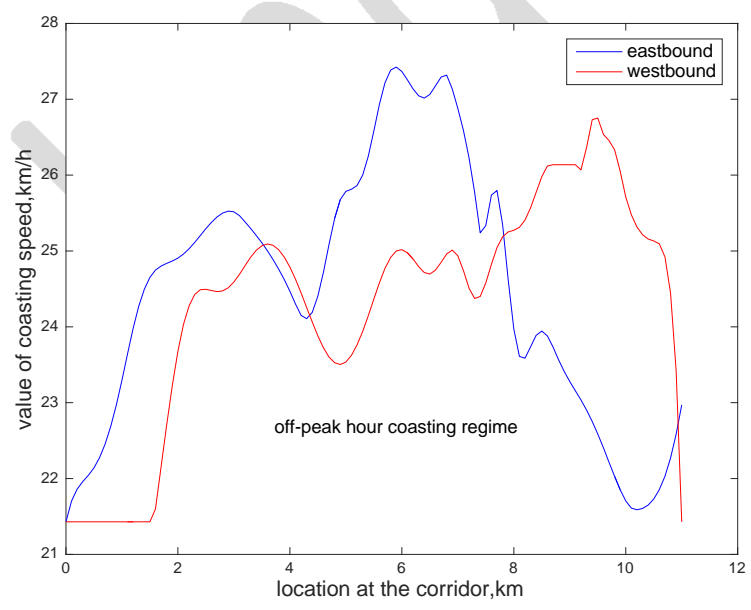

(c) Lithium-ion bus coasting profile

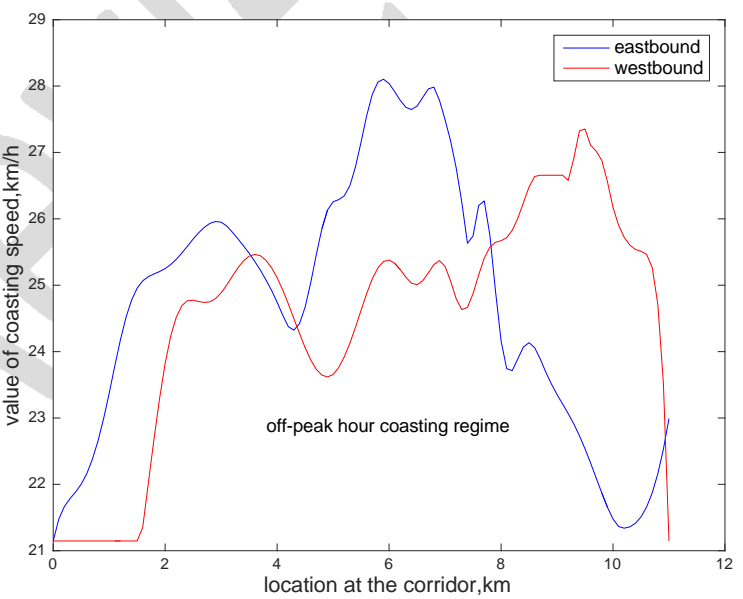

(b) CNG bus coasting profile

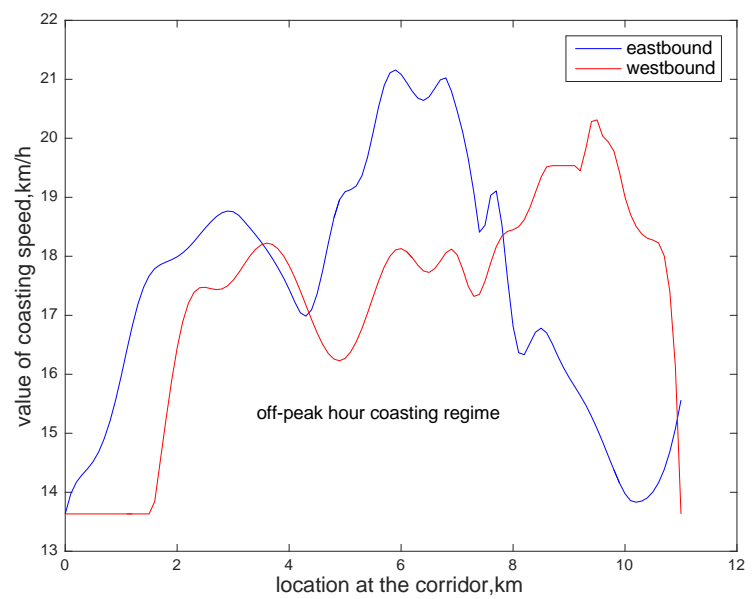

(d) Diesel bus coasting profile

\section{FIGURE 5 Coasting speed profiles in off-peak hour for four vehicle types}


From the two figures above, the optimal coasting speed profiles of four different vehicle types in the same period have the similar trend, but with distinguishing differences in average values. By discretizating the coasting speed functions, we can obtain the average values of coasting speeds in peak/off-peak hour on two directions. The results are summarized in Table 4, from which supercharge bus has the highest average coasting speed regardless of the time period. By contrast, diesel bus has the lowest average coasting speed. The results are reasonable because the diesel bus has the highest per-kilometer energy cost. In order to conserve energy, it's more beneficial to coast, as coasting regime will have less energy consumption than cruising regime. As for supercharge bus, whose per-kilometer energy cost is slight, it's more profitable to drive at cuising speed in order to save travel time.

\section{TABLE 4 Optimal Values of Coasting Speed in Different Periods on Two Directions}

\begin{tabular}{|l|l|l|l|l|}
\hline Vehicle Types & $\begin{array}{l}\boldsymbol{v}_{\boldsymbol{c o , e b}} \text { in peak } \\
(\mathbf{k m} / \mathbf{h})\end{array}$ & $\begin{array}{l}\boldsymbol{v}_{\boldsymbol{c o}, \boldsymbol{e b}} \text { in off-peak } \\
(\mathbf{k m} / \mathbf{h})\end{array}$ & $\begin{array}{l}\boldsymbol{v}_{\boldsymbol{c o , w b}} \text { in peak } \\
(\mathbf{k m} / \mathbf{h})\end{array}$ & $\begin{array}{l}\boldsymbol{v}_{\boldsymbol{c o , w b}} \text { in off-peak } \\
(\mathbf{k m} / \mathbf{h})\end{array}$ \\
\hline Supercharge & 35.23 & 36.12 & 35.42 & 35.00 \\
\hline CNG & 25.00 & 23.07 & 25.57 & 22.80 \\
\hline Lithium-ion & 28.79 & 24.95 & 29.23 & 24.71 \\
\hline Diesel & 20.52 & 16.81 & 21.14 & 16.50 \\
\hline
\end{tabular}

Driving regimes have direct impact on operation cost. In light of this, a system-cost comparison is conducted between optimized systems that introducing coasting regime and the one without considering coasting regime. The results are concluded in Table 5 and the operation costs in no-coasting system increase by up to $7 \%$, while user costs decrease more than $12.9 \%$, mainly in access/egress cost. The reason is that, introducing coasting regime will reduce the number of stops along corridor, leading to an increase in access/egress cost. However, the in-vehicle costs for two models are in neighborhood (with difference less than 5\%), which means the travel time is closed for two systems, even when coasting regime is added. As a result, the distance traveled under cruising regime (with higher per-kilometer cost) will decrease. That's the reason why operation cost will decrease when introducing coasting regime in the system. Thus, coasting regime has a positive impact in view of operator, but passengers should accept a higher user cost. To summarize, for clean-energy buses (i.e., supercharge buses and Lithium-ion buses), it's more profitable to drive at cruising speed, while for conventional buses (i.e., CNG buses and diesel buses), introducing coasting regime is justifiable, considering the cost saving in operation and energy.

TABLE 5 System Cost with Coasting Regime vs. System Cost Without Coasting Regime

\begin{tabular}{|c|c|c|}
\hline \multicolumn{3}{|c|}{ Supercharge Bus Route Design } \\
\hline System metrics & No coasting regime & With coasting regime \\
\hline$h_{\text {peak }}, \min$ & 7.59 & 7.76 \\
\hline$h_{\text {off-peak }}, \min$ & 8.94 & 8.12 \\
\hline Spacing $_{e b}, \mathrm{~km}$ & 0.50 & 0.65 \\
\hline Spacing $_{w b}, \mathrm{~km}$ & 0.48 & 0.61 \\
\hline$C_{u}, \$ /$ day & $4,850.2$ & $5,567.4$ \\
\hline$C_{O}, \$ /$ day & $2,762.2$ & $2,559.9$ \\
\hline
\end{tabular}




\begin{tabular}{|c|c|c|}
\hline$T C, \$ /$ day & $7,612.4$ & $8,127.3$ \\
\hline \multicolumn{3}{|c|}{ CNG Bus Route Design } \\
\hline$h_{\text {peak }}, \min$ & 6.69 & 6.55 \\
\hline$h_{\text {off-peak }}, \min$ & 11.92 & 10.68 \\
\hline Spacing $_{\text {eb }}, \mathrm{km}$ & 0.50 & 0.65 \\
\hline Spacing $_{w b}, \mathrm{~km}$ & 0.46 & 0.61 \\
\hline$C_{u}, \$ /$ day & $4,931.7$ & $5,594.7$ \\
\hline$C_{O}, \$ /$ day & $2,596.6$ & $2,398.2$ \\
\hline$C_{P}$, \$/day & 62.5 & 88.0 \\
\hline$T C, \$ /$ day & $7,590.8$ & $8,080.9$ \\
\hline \multicolumn{3}{|c|}{ Lithium-ion Battery Bus Route Design } \\
\hline$h_{\text {peak }}, \min$ & 8.12 & 8.30 \\
\hline$h_{\text {off-peak }}, \min$ & 11.95 & 10.30 \\
\hline Spacing $_{e b}, \mathrm{~km}$ & 0.52 & 0.69 \\
\hline Spacing $_{w b}, \mathrm{~km}$ & 0.50 & 0.65 \\
\hline$C_{u}$, \$/day & $5,248.6$ & $5,911.1$ \\
\hline$C_{O}, \$ /$ day & $2,999.9$ & $2,818.0$ \\
\hline$T C, \$$ day & $8,248.5$ & $8,729.1$ \\
\hline \multicolumn{3}{|c|}{ Diesel Bus Route Design } \\
\hline$h_{\text {peak }}, \min$ & 7.94 & 7.60 \\
\hline$h_{\text {off-peak }}, \min$ & 15.40 & 12.89 \\
\hline Spacing $_{e b}, \mathrm{~km}$ & 0.52 & 0.69 \\
\hline Spacing $_{w b}, \mathrm{~km}$ & 0.50 & 0.65 \\
\hline$C_{u}, \$ /$ day & $5,456.4$ & $6,305.8$ \\
\hline$C_{O}, \$ /$ day & $2,671.5$ & $2,688.9$ \\
\hline$C_{P}, \$ /$ day & 270.6 & 62.5 \\
\hline$T C, \$ /$ day & $8,398.5$ & $9,057.2$ \\
\hline
\end{tabular}

\section{Cost Effectiveness Comparison}

This part will analyze the life cycle cost for four vehicle types, which is from a macroscopic view. From Table 3, we can find the most economical vehicle type is CNG buses. Historical data shows that the maintenance cost for $\mathrm{CNG}$ and diesel bus will increase by year, even though their initial capital cost is lower. As a result, the cumulative costs of conventional buses in a life span will also be expensive. According to the maintenance cost data that Shu Tong Transportation Agency provided, clean-energy buses have a constant maintenance cost but a high initial capital cost. Thus, there exists a trade-off: which type is the most economical in a life span ( 8 years). Inspaired by the previous studies $(2,26)$, which explored the varying maintenance cost by years in terms of diesel buses and CNG buses by using monthly maintenance data, we can roughly analyze the life cycle cost of our buses. The relationships of maintenance cost changing by year for diesel bus and CNG bus are shown respectively:

$y=0.025+0.029 * z$, which $y$ is presented the cost of maintenance per kilometer $(\$ / \mathrm{km})$ for diesel bus, $z$ is the bus age (years). 
$y=0.02+0.017 * z$, which $y$ is the maintenance cost per kilometer for CNG bus $(\$ / \mathrm{km}), z$ is the bus age (years).

We investigated a cost comparison for four bus types as shown in Figure 6. The results present that without including the pollutant cost into calculation, the cumulative costs of CNG bus will surpass those of supercharge bus after $13^{\text {th }}$ year. On the contrary, when pollutant costs for conventional buses (i.e., CNG buses and diesel buses) are taken into consideration, supercharge bus will outperform other bus types after 8 years, which is still out of a life span. Thus, clean-energy buses are less competive than conventional buses unless the government provides subsidies.

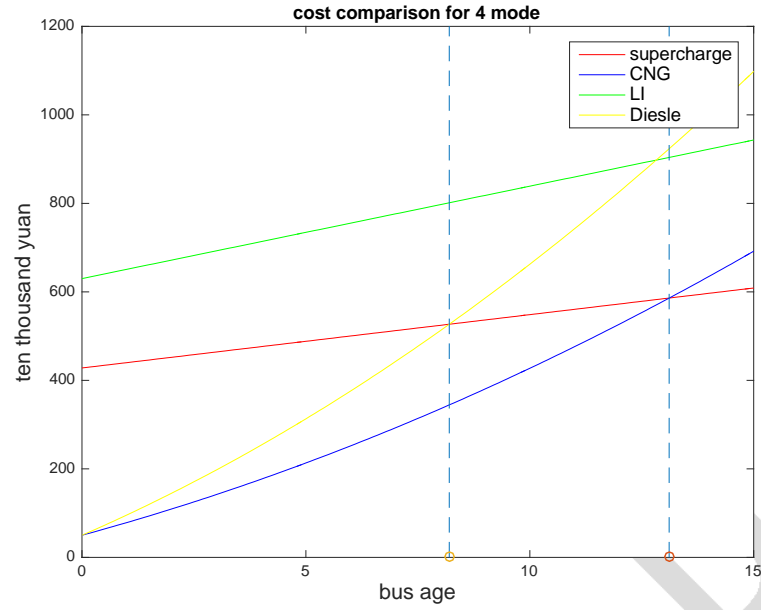

(a) Life-cycle analysis without pollutant costs

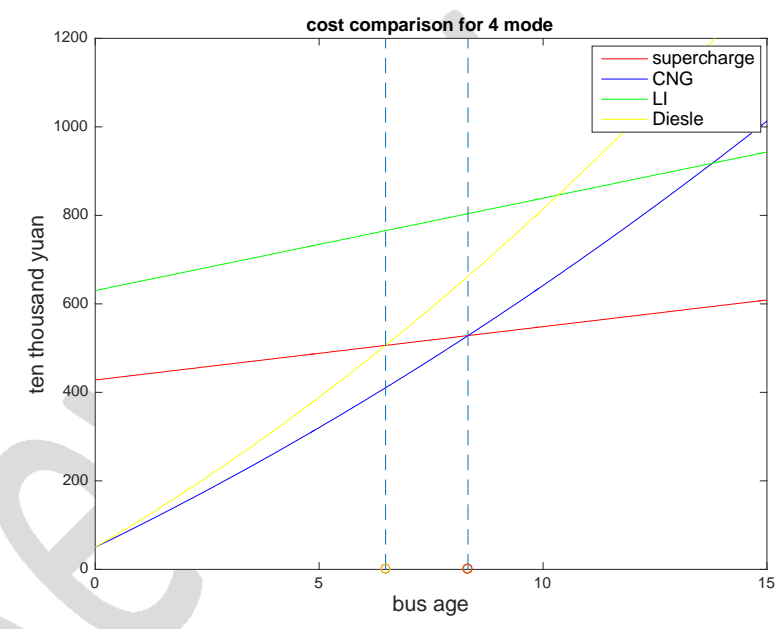

(b) Life-cycle analysis with pollutant costs

\section{FIGURE 6 Life-span cost comparison}

\section{CONCLUSION AND FUTURE EXTENSION}

In this research, we developed a muti-period continuum approximation to optimize total cost including user cost, operator cost, and pollutant cost, where environmental impact and various driving regimes are explicitly considered. The proposed model is applied to four different vehicle types to optimize stop locations and service headway. The optimization of a real-word bus route results in significant reduction of total cost (over 50\%). Comparing with current transit design, the average stop spacing is increased by $31.3 \%$, and the peak-hour headway is decreased by up to $31 \%$. The accuracy of proposed model is verified by a discrete model with error less than $3 \%$. The huge gap of total system cost between current design and optimized design indicates that current design might not well fit the demand, adjustment should be done in terms of stop locations and headway.

To investigate the effect of coasting regime, the optimal coasting profiles and the average values on two directions in multiple periods is compared in terms of different bus types. The results indicate that clean-energy buses have a shorter coasting distance while conventional buses need to coast longer in order to conserve energy. The analysis of the effect of coasting regime on operation cost suggest that introducing coasting regime will reduce operation cost (by up to 7\%) but increase user cost (by up to 13\%).

In the life-span cost effectiveness comparison amongst four different vehicle types, the economic feasibility of supercharge bus has been discussed. On a life-span scale (normally 8 
years), the total cost of supercharge will be the lowest among four vehicle type after $8^{\text {th }}$ years, when pollutant costs are considered. It provides an insight that from the prespective of operator, shifting conventional buses to new energy buses is not profitable unless subsidies are provided by government.

For future extension, it is interesting to compare the stop-skip service with current all-stop design. Additionally, the effect of coasting for different transit modes, such as rail and Bus Rapid Transit (BRT) system can be further studied.

\section{ACKNOWLEDGMENTS} authors thank the Shu Tong Transportation Agency for providing the useful data for case study.

\section{Author contribution statement:}

"The authors confirm contribution to the paper as follows: study conception and design:

Yue Su, Guo Lu, Wenbo Fan; data collection: Yue Su; analysis and interpretation of results: Yue Su, Wenbo Fan; draft manuscript preparation: Yue Su, Wenbo Fan, Xiaobo Liu. All authors reviewed the results and approved the final version of the manuscript"

\section{REFERENCES}

1. Fastcompany:https://www.fastcompany.com/40506877/by-2018-every-bus-in-this-chines e-megacity-will-be-electric

2. Feng, W., Figliozzi, M.A. Bus Fleet Type and Age Replacement Optimization: A Case Study Utilizing King County Metro Fleet Data. Presented at the 12th Conference on Advanced Systems for Public Transport. Santiago, Chile., 2012

3. Vuchic V. and Newell G. Rapid Transit Inter-stop Spacing for Minimum Travel Time. Transportation Science, 1968. 2: 359-374.

4. $\quad$ Furth, P. G., Rahbee, A. B. Optimal Bus Stop Spacing Through Dynamic Programming and Geographic Modeling. Transportation Research Record: Journal of the Transportation Research Board, 2000. 1731: 15-22

5. Mekuria, M.C., P.G. Furth. Optimization of Spacing of Transit Stops on a Realistic Street Network. Transportation Research Record: Journal of the Transportation Research Board, CD-ROM. Transportation Research Board of the National Academies, Washington, D.C., 2012, pp. 29-37

6. Ceder, A., Butcher, M., Wang, L. Optimization of Bus Stop Placement for Routes on Uneven Topography. Transportation Research Part B, 2015. 74: 40-61

7. Ibarra-Rojas, O.J., Delgado, F., Giesen, R., Muñoz, J.C. Planning, Operation, and Control of Bus Transport Systems: A Literature Review. Transportation Research Part B, 2015. 77: $38-75$

8. Newell, G.F. Scheduling, Location, Transportation and Continuum Mechanics; Some Simple Approximations to Optimization Problems. SIAM Journal of Applied Mathematics, 1973. 25: 346-360

9. Hurdle V.F. Minimum Cost Locations for Parallel Public Transit Lines. Transportation Science, 1973. 7: 340-350.

10. Wirasinghe S.C., Hurdle V.F., Newell G.F. Optimal Parameters for a Coordinated Rail and Bus Transit System. Transportation Science, 1977. 11(4): 359-374. 

11. Wirasinghe S.C. Nearly Optimal Parameters for a Rail/Feeder-bus System on a Rectangular Grid. Transportation Research Part A, 1980. 14(1): 33- 40
12. Wirasinghe S.C, Ghoneim NS. Spacing of Bus Stops for Many to Many Travel Demand. Transportation Science 1981. 15: 210-221
13. Vaughan R. J. Optimum Polar Networks for an Urban Bus System with a Many-to-Many Travel Demand. Transportation Research Part B 1986. 20: 155-224
14. Vaughan R.J., and Cousins E.A. Optimum Location of Stops On a Bus Route. Presented at the Seventh International Symposium on Transportation and Traffic Theory, 1977, pp. 697-716
15. Daganzo, C. Structure of Competitive Transit Networks. Transportation Research Part B 44, 2010, pp. 434-466.
16. Medina, M., Giesen, R., Muñoz, J. Model for the Optimal Location of Bus Stops and Its Application to a Public Transport Corridor in Santiago, Chile. Transportation Research Record: Journal of the Transportation Research Board, 2013. 2352: 84-93

17. Gu, W., Amini, Z., Cassidy, M.J. Exploring Alternative Service Schemes for Busy Transit Corridors. Transportation Research Part B, 2016. 93: 126-145

18. Fan, W., Mei, Y., Gu, W. Optimal Design of Intersecting Bimodal Transit Networks in a Grid City. Transportation Research Part B, 2018. 111: 203-226

19. Daganzo, C. Logistic Systems Analysis. Springer, Heidelberg, 2005

20. Byrne, B.F. Cost Minimizing Positions, Lengths and Headways for Parallel Public Transit Lines Having Different Speeds. Transportation Research, 1976. 10: 209214

21. Sivakumaran, K., Li, Y., Cassidy, M., Madanat, S., 2012. Cost-savings Properties of Schedule Coordination in a Simple Trunk-and-feeder Transit System. Transportation Research Part A, 2012. 46: 131-139

22. Amirgholy, M., Shahabi, M., Gao, H.O. Optimal Design of Sustainable Transit Systems in Congested Urban Networks: A Macroscopic Approach. Transportation Research Part E. 2017. 103: 261-285

23. Vuchic, V. Urban Transit Systems and Technology. John Wiley \& Sons, Inc., Hoboken, NJ, 2007

24. Qu, H., Liu, X., Chien, S. Improving Vehicle Emission of Bus Transit with Integrated Service and Different Vehicle Size. Presented at the 86th Transportation Research Board Annual Meeting, 2015, Washington, DC

25. Yu Qian. Urban Diesel Bus Emission and Its Application. Doctor Dissertation, Southeast University, 2016

26. Leslie, E., Matthew, P. Fuel Cell Buses in U.S. Transit Fleets: Current Status 2017.November, 2017. https://www.nrel.gov/docs/fy18osti/70075.pdf 